\title{
A Model System for Feralizing Laboratory Mice in Large Farmyard-Like Pens
}

\begin{abstract}
Henriette Arnesen 1,2, Linn Emilie Knutsen', Bente Wabakken Hognestad', Grethe Marie Johansen ${ }^{1}$, Mats Bemark ${ }^{3,4}$, Oliver Pabst ${ }^{5}$, Anne Kristine Storset ${ }^{1}$ and Preben Boysen ${ }^{\text {* }}$

${ }^{1}$ Faculty of Veterinary Medicine, Norwegian University of Life Sciences, Oslo, Norway, ${ }^{2}$ Faculty of Chemistry, Biotechnology and Food Science, Norwegian University of Life Sciences, Aas, Norway, ${ }^{3}$ Department of Microbiology and Immunology, Institute of Biomedicine, Sahlgrenska Academy, University of Gothenburg, Gothenburg, Sweden, ${ }^{4}$ Region Västra Götaland, Sahlgrenska University Hospital, Department of Clinical Immunology and Transfusion Medicine, Gothenburg, Sweden,

${ }^{5}$ Institute of Molecular Medicine, RWTH Aachen University, Aachen, Germany
\end{abstract}

Laboratory mice are typically housed under extremely clean laboratory conditions, far removed from the natural lifestyle of a free-living mouse. There is a risk that this isolation from real-life conditions may lead to poor translatability and misinterpretation of results. We and others have shown that feral mice as well as laboratory mice exposed to naturalistic environments harbor a more diverse gut microbiota and display an activated immunological phenotype compared to hygienic laboratory mice. We here describe a naturalistic indoors housing system for mice, representing a farmyard-type habitat typical for house mice. Large open pens were installed with soil and domestic animal feces, creating a highly diverse microbial environment and providing space and complexity allowing for natural behavior. Laboratory C57BL/6 mice were co-housed in this system together with wild-caught feral mice, included as a source of murine microbionts. We found that mice feralized in this manner displayed a gut microbiota structure similar to their feral cohabitants, such as higher relative content of Firmicutes and enrichment of Proteobacteria. Furthermore, the immunophenotype of feralized mice approached that of feral mice, with elevated levels of memory T-cells and late-stage NK cells compared to laboratory-housed control mice, indicating antigenic experience and immune training. The dietary elements presented in the mouse pens could only moderately explain changes in microbial colonization, and none of the immunological changes. In conclusion, this system enables various types of studies using genetically controlled mice on the background of adaptation to a high diversity microbial environment and a lifestyle natural for the species.

Keywords: animal model, mice, feral mice, feralized mice, trained immunity, immune experience, gut micobiota, naturalistic environment

\section{INTRODUCTION}

The common habitat for the house mouse (Mus musculus) is on the ground, typically close to larger animals like humans and their livestock, and the genetic basis for all research mice evolved in such environments (Boursot et al., 1993). Colonization by a host-specific microbiota is necessary to develop essential parts of the mucosal immune system in mice (Cebra, 1999; Chung et al., 2012), 
and expression of effector- as well as tolerance-associated immune genes are upregulated following microbial colonization (El Aidy et al., 2012). Nevertheless, mice are usually studied under strictly hygienic laboratory conditions. Hence, concerns have been raised whether hygienically raised laboratory (lab) mice will reach a level of immune maturation that fully recapitulates the immune response in a mammal (Tao and Reese, 2017). Large variations in microbiota and cellular composition of the gut mucosa have been observed between animal facilities, accompanied by different immune phenotypes and experimental performance (Ivanov et al., 2009; Kriegel et al., 2011; Jakobsson et al., 2015; Rausch et al., 2016; Franklin and Ericsson, 2017). Thus, an artificial between-lab variability may have replaced natural variability in the course of comprehensible efforts to standardize the world's most used animal model.

Theories have postulated that a modernized lifestyle has led to a loss of proximity to a diverse range of microbes and parasites, thus removing balancing factors in the immune homeostasis, which may explain an increase of inflammatory diseases and cancer (Hunter, 2020). A major current research field addresses how colonizing microbes, including bacteria, parasites and even viruses, may affect the immune system to generate a lasting and general protection from various diseases. Beyond specific immunity, recent evidence shows how innate immune cells may undergo long-lasting reprogramming following microbial challenges, sometimes referred to as trained immunity (Oh et al., 2014; Honda and Littman, 2016; Netea et al., 2020). Adaptive immune cells may also be primed in a similar manner (Muraille and Goriely, 2017). The concept of immune training has been associated with enhancement of immune responses to vaccines and infections as well as to anti-inflammatory actions (Quinn et al., 2019). The outcome of immune training for a particular disease may thus point in either direction and needs to be explored empirically in organisms exposed to diverse microbial cues.

This background gives a rationale to develop animal models reflecting more realistic ecological contexts (Flies and Wild Comparative Immunology Consortium, 2020). In contrast to the widespread use of hygienically raised inbred mice, studies investigating the microbiota and immunity of mice under more naturalistic conditions have only recently emerged. We and others have demonstrated that feral (wild-caught) mice had an immunological steady state different from lab mice (Devalapalli et al., 2006; Abolins et al., 2011, 2017, 2018), as well as a thicker mucus layer in the gut (Jakobsson et al., 2015). In an effort to decipher the impact of environment, one study found profound changes in the immune system of inbred mice following co-housing with "dirty" pet store mice, approaching

Abbreviations: B6, C57BL/6 inbred mouse strain; CM T-cell, Central memory T-cell; EM T-cell, Effector memory T-cell; Exp. 1/Exp. 2, Experiment 1/Experiment 2; Fzd, Feralized (here: female) B6 mice; Fzd ${ }^{\mathrm{F}}, \mathrm{B} 6$ females feralized in the presence of female feral mice; $\mathrm{Fzd}^{\mathrm{M}}$, B6 females feralized in the presence of male feral mice; Ig, Immunoglobulin; IL, Interleukin; IVC, Individually ventilated cage; KLRG1, Killer cell lectin-like receptor subfamily G member 1; NRP-1, Neuropilin1; OTU, Operational taxonomic unit; PCA, Principal component analysis; PLN, Peripheral lymph node; pTreg, Peripherally induced regulatory T-cell; Rm1, Rat and Mouse No.1 diet ( ${ }^{\mathrm{TM}}$ of Special Diet Services); SPF, Specific pathogen-free; Treg, Regulatory T-cell. phenotypes found in feral mouse as well as adult humans (Beura et al., 2016). In another, pre-infection of inbred mice with selected common mouse pathogens resulted in stronger vaccine responses (Reese et al., 2016). Furthermore, by transplanting feral mouse feces (Rosshart et al., 2017) or by transferring microbiota vertically from feral surrogate mothers (Rosshart et al., 2019), "wildling" lab mice were shown to develop a trained immune system and increased protection against disease. The latter study demonstrated the translational gain by using naturalized mice, as wildling mice behaved immunologically human-like in two clinical settings where conventional lab mice had failed to predict the response. Another study showed that the provision of soil heaps in mice cages modified the gut microbiota and repressed Th2-driven inflammation, in support of the "hygiene hypothesis" (Ottman et al., 2019). However, in all the studies mentioned above, lab mice remained in conventional cages, with limitations of space and behavioral opportunities relative to a wild house mouse lifestyle. A recently described model where mice were kept in large outdoor enclosures, showed altered microbiota, a shift toward Th1-type immunity and an increased susceptibility to helminth infection (Leung et al., 2018; Lin et al., 2020; Yeung et al., 2020). While offering a habitat clearly representing wild conditions, this setup allows limited surveillance of the animals and may prove inaccessible for most researchers.

We present a naturalistic environment housing system for mice consisting of large indoor enclosures (pens) containing farmyard-like elements such as fecal content from farm animals, soil and plant materials, with spatial living conditions reflecting a natural habitat. In a set of experiments, C57BL/6 mice were feralized under these conditions in the presence of feral house mice, serving as a natural source of mouse microbes, including pathogens and parasites. We show that feralization lead to a significant conversion of the gut microbiota composition, and to immunological parameters associated with antigenic experience and immune training.

\section{MATERIALS AND METHODS}

\section{Animals and Experimental Design}

A mouse pen housing system was designed at The Norwegian University of Life Sciences (NMBU) by escape-proofing pig pens with sheets of galvanized steel, each pen measuring 2.0 $\times 2.5 \times 1.25 \mathrm{~m}(\mathrm{WxDxH})$ on concrete floor (Figures 1A-E and Supplementary Video S1). Pens were enriched with wood shavings, organic garden soil, compost, twigs, hay and fecal content from pigs, cows and horses. Oat and carrot sprouts were planted occasionally to provide fresh plants as would be encountered in a farmyard. Wooden pallets were used as stepping platforms for personnel to avoid disturbing the habitats or crushing animals, also contributing to environmental complexity and shelter. Standard nippled drinking bottles provided water. Small wooden boxes were provided for nesting and sheltering. In Experiment (Exp.) 1, surveillance cameras with infrared sensors were used for continuous monitoring. 

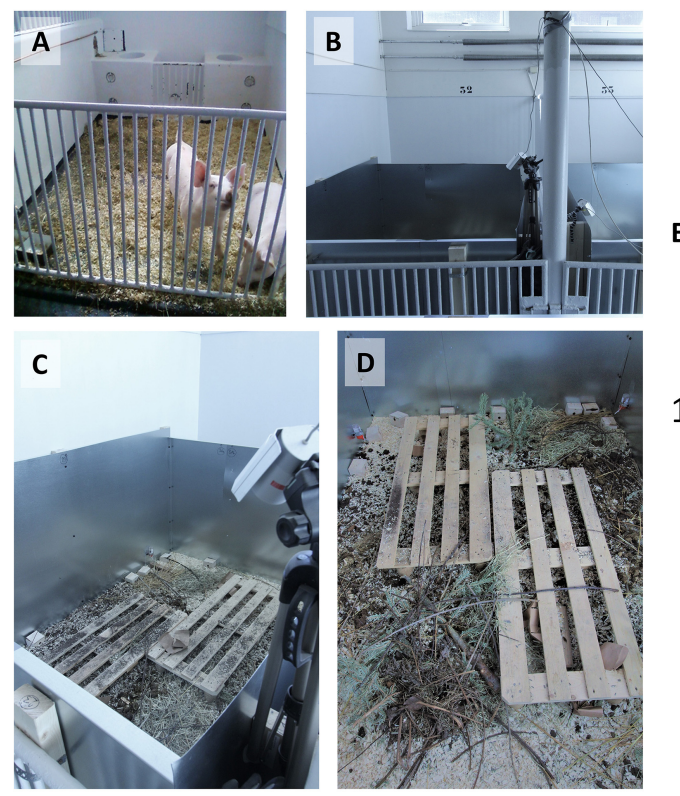

$\mathbf{E}$

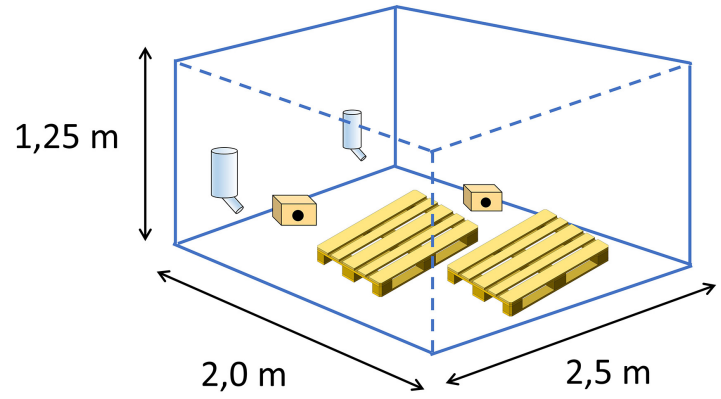

FIGURE 1 | Construction of mouse pens. Original pig pens in the large animal clinic at NMBU shown in (A) were modified with steel sheets (B,C) and equipped with surveillance cameras (B,C). (D) Contents of mouse pens as outlined in section "Materials and Methods." (E) Schematic representation of pen construction, showing pallets, wooden houses and drinking bottles (pallet graphics from https://publicdomainvectors.org/).

Following purchase, C57BL/6N (B6) specific pathogen-free (SPF) mice (Charles River/Scanbur, Norway) were acclimatized for 1 week in individually ventilated cages (IVCs) under SPF conditions at NMBU. Feral house mice were captured in domestic animal farms in south-eastern Norway by overnight deployment of Ugglan Special No1 live traps (Grahnab, Gnosjö, Sweden), equipped with wood shavings, fresh fruit and peanut butter as bait, as previously described (Boysen et al., 2011). Representatives of these catches were subtyped as Mus musculus ssp. musculus, with a minor contribution of ssp. domesticus as reported previously (Knutsen et al., 2019). The ages of feral mice could not be determined, but only visibly adult individuals were included. Mice were individually marked using ear punch or microchip injected subcutaneously (Nonatec Lutronic, Rodange, Luxembourg). Feral and B6 mice were released simultaneously into pens.

Experiments and housing design were approved by the National Animal Research Authority in Norway (FOTS 4788, 6801, and 8080). Feral mice capture was approved by The Norwegian Directorate for Nature Management (2012/693 and 2014/7215).

In Exp. 1 (Figure 2), female B6 mice aged 53-77 days were feralized by housing in pens together with feral mice for 9 weeks, divided into two subgroups: In one pen, 15 female B6 mice were co-housed with 10 female feral mice $\left(\mathrm{Fzd}^{\mathrm{F}}\right.$; feralized with feral females). In a second pen, 15 female B6 mice were co-housed with 4 male feral mice $\left(\mathrm{Fzd}^{\mathrm{M}}\right.$; feralized with feral males). Fzd ${ }^{\mathrm{M}}$ mice produced several litters of hybrid offspring excluded from the study. To provide a diet reflecting food sources in a natural setting, we provided an unprocessed wild bird seed mix consisting of sunflower seeds (25\%), sorghum
(25\%), oat (25\%), and wheat (25\%) (Wild bird mix, Plantasjen, Köping, Sweden), mixed with standard "chow" pellets (Rm1, Special Diet Services, United Kingdom/Scanbur, Norway) ad lib on the ground (see Supplementary Table S1 for nutrient composition.) In addition, pen mice had access to a variation of plant material, including dried hay, spruce twigs collected outdoors, and occasional fresh lettuce, carrots and fruits. 20 female B6 mice of the same cohort were housed in cages under SPF conditions as controls, receiving standard chow diet only, to maintain typical lab conditions.

In Exp. 2 (Figure 2), 15 female B6 mice aged 28 days were feralized in mouse pens with 8 female adult feral mice for 14 weeks (Fzd), while 15 B6 females were kept in cages as SPF controls. Feeding regimen as described above. As the feralized mice were fed a natural diet in the previous experiments, we designed Exp. 3 (Figure 2) to assess the effects of the major dietary sources of the previous two experiments, carried out in IVCs under conventional lab conditions. 30 female B6 mice (source, age and gender as in Exp. 2) were housed for 14 weeks in cages of 5 mice per cage. The animals were randomized into two groups receiving either chow or a combinatory diet of chow and seed mix (the latter hereafter referred to as seed group for simplicity).

The mice were exposed to human caretakers in the pens on a daily basis, but direct handling was minimized, and mice were not re-captured until termination of the experiment. Only mice that were clinically healthy condition at termination were included in the studies. All mice were euthanized by neck dislocation, followed by immediate exsanguination by cardiac puncture, weighing and measuring, and dissection of sample tissues. 


\section{Experiment 1}

Farm environment vs. SPF conditions. Adult $B 6$ mice feralized ( $F z d$ ) in pens equipped with farmyard elements and the presence of feral mice.

One pen: Male ferals with female B6 (FzdM)

One pen: Female ferals with female B6 (FzdF) Duration: 9 weeks
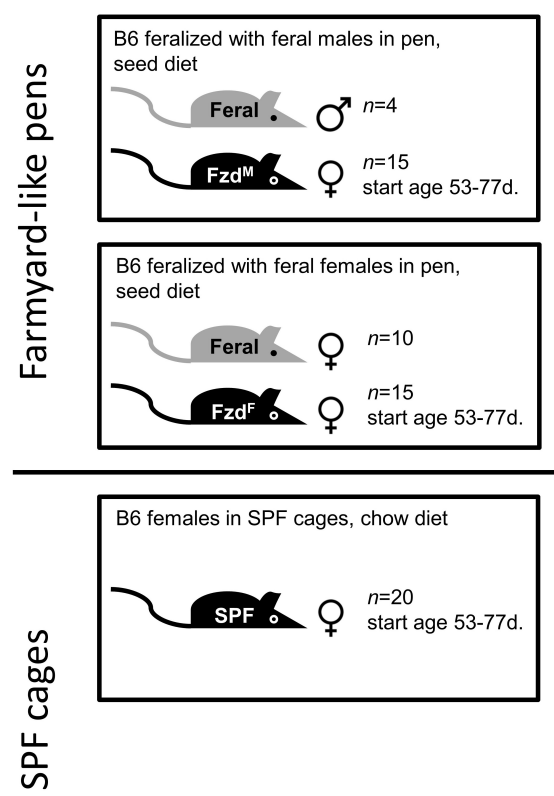

Experiment 2

Farm environment vs. SPF conditions. Juvenile female B6 mice feralized (Fzd) in pens equipped with farmyard elements and the presence of female feral mice.

Duration: 14 weeks

\section{Experiment 3}

Seed vs. chow diet in SPF conditions. Juvenile female B6 mice housed in SPF cages with either of the two diets:

Chow diet $=\mathrm{Rm} 1$ pellets

Seed diet $=$ Wild bird mix plus Rm1 pellets

Duration: 14 weeks
B6 females in SPF cages, chow diet

B6 females in SPF cages, chow diet

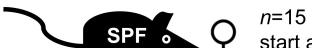
start age $\leq 28 \mathrm{~d}$

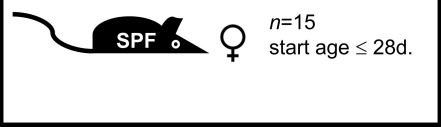

B6 females in SPF cages, seed diet

SPF $Q \quad \begin{aligned} & n=15 \\ & \text { start }\end{aligned}$ start age $\leq 28 \mathrm{~d}$.

FIGURE 2 | Graphical representation of the experimental design of the three experiments described in this study, as detailed in section "Materials and Methods."

\section{Isolation of Cells and Serum}

Cells harvested from tissues using a GentleMACS dissociator and mouse Spleen Dissociation Kit (Miltenyi Biotech, Bergisch Gladbach, Germany) according to the manufacturer's instructions. Splenic suspensions were briefly treated with $\mathrm{NH}_{4} \mathrm{Cl}$ solution to lyse erythrocytes. Single-cell suspensions were prepared using a $70 \mu \mathrm{m}$ cell strainer (BD Biosciences) and concentrations standardized after counting using a Countess automated cell counter (Thermo Fisher Scientific). Serum was isolated from blood following centrifugation of clotted whole blood at 3,000 $\mathrm{g}$ for $5 \mathrm{~min}$.

\section{Microbial Community Analyses}

For microbial community analyses, fecal pellets were flash frozen in liquid $\mathrm{N} 2$ after collection and stored at $-80^{\circ} \mathrm{C}$. DNA extraction, library preparation and $16 \mathrm{~S}$ rDNA 454 pyrosequencing were conducted as described previously (Lindner et al., 2015). Briefly, DNA was isolated and purified with QIAamp DNA Stool Mini Kit (Qiagen) according to manufacturer's manual. Libraries we generated with a primer set covering the $\mathrm{V} 1-\mathrm{V} 3$ regions of the 16s rRNA gene (8F/541R). 16S rRNA gene amplicons were purified by gel electrophoresis followed by gel extraction (QIAquick Gel Extraction kit, Qiagen). Amplicons were prepared with the GS FLX Titanium SV emPCR kit (Lib-A) for 454 pyrosequencing on the Genome Sequencer FLX system (Roche) according to manufacturer's instructions. In Exp. 2 and 3 , feces was collected from all individuals at baseline (t0) and termination following 14 weeks of feralization ( $\mathrm{t} 1$ ).

Raw reads were processed using the Integrated Microbial Next Generation Sequencing (IMNGS) pipeline (Lagkouvardos et al., 2016) based on the UPARSE approach. Briefly, sequences were demultiplexed, trimmed to the first base with a quality score $>3$ and paired. Sequences with $>1000$ nucleotides and assembled reads with expected error of $>3$ were excluded from the analyses (Exp. 2, USEARCH 8.0; Exp. 3, USEARCH 8.1) (Edgar, 2010). Remaining reads were trimmed by 10 nucleotides at forward and reverse end. The presence of chimeras was tested with UCHIME (Edgar et al., 2011). Operational taxonomic units (OTUs) were clustered at $97 \%$ sequence similarity (Edgar, 2010) (Exp. 2, USEARCH 8.0; Exp. 3, USEARCH 8.1), and only those with a relative abundance of $>0.50 \%$ (Exp. 2) or $>0.25 \%$ (Exp. 3) in at least one sample were kept. Taxonomies were assigned at $80 \%$ confidence level with the RDP classifier (Wang et al., 2007) (version 2.11, training set 15). Sequences were aligned with 
MUSCLE (Edgar, 2004) and trees were generated with Fasttree (Price et al., 2010). In Exp. 2 the analyzed dataset included $1,207,683$ quality- and chimera-checked sequences ranging from 6,527 to 48,172 per sample, representing a total of 338 OTUs. One individual in the Fzd group was excluded from analyses due to abnormally high sequence depth $(152,009)$. In Exp. 3 the analyzed dataset included 3,481,304 quality- and chimerachecked sequences ranging from 39,504 to 131,663 per sample, representing a total of 220 OTUs. Sequencing files from Exp. 2 and Exp. 3 are deposited to the Sequence Read Archive and are available under the accession number PRJNA668303.

\section{Flow Cytometry and in vitro T-Cell Stimulation}

Immunophenotyping was carried out by incubating single-cell suspensions in phosphate-buffered saline (PBS) with 0.5\% bovine serum albumin and $10 \mathrm{mM} \mathrm{NaN3}$ on ice. After FcR-blocking with anti-CD32/16 antibody (eBioscience), cells were stained with Live/Dead Fixable Yellow Dead Cell Stain Kit (Thermo Fisher Scientific) followed by incubation with combinations of monoclonal antibodies as listed in Supplementary Table S2. For intracytoplasmatic staining, cells were treated with Intracellular Fixation and Permeabilization Buffer Set, or with Foxp3/Transcription Factor Staining Buffer Set for intranuclear antigens (both eBioscience), according to the manufacturer's instructions. Fluorescence levels were measured using a Gallios 3-laser flow cytometer and analyzed using Kaluza 1.2 software (Beckman Coulter). Cells were gated as shown in Supplementary Figure S1, using single cell staining, omission of antibodies and matched isotypes as controls. For stimulation assays, splenocytes were cultured at concentration of $2 \times 10^{6}$ cells $/ \mathrm{ml}$ together with Dynabeads Mouse T-Activator CD3/CD28 (Thermo Fisher Scientific) at a 1:1 ratio, in RPMI (Gibco) l-glutamine supplemented with $60 \mu \mathrm{g} / \mathrm{ml}$ penicillin, $100 \mu \mathrm{g} / \mathrm{ml}$ streptomycin, $1 \mathrm{mM}$ sodium pyruvate, $50 \mu \mathrm{M}$ 2-mercaptoethanol, non-essential amino acids (all Gibco/Invitrogen), 10\% fetal calf serum (PAA) and $30 \mathrm{U} / \mathrm{ml}$ recombinant murine ( $\mathrm{rm}$ )IL-2 (eBioscience) for $48 \mathrm{~h}$. Brefeldin A $(10 \mu \mathrm{g} / \mathrm{ml}$; Sigma $)$ was added $4 \mathrm{~h}$ before harvesting, followed by immunophenotyping.

\section{Multiplex Assays}

Cytokines were measured in serum using the following multiplex assays: Bio-Plex Pro Mouse Cytokine 8-plex panel (\#M60000007A) supplemented with IL-6 and IL-17A singleplex, Bio-Plex Pro ${ }^{\text {TM }}$ TGF- $\beta$ 3-plex Assay (\#171W4001M) (Bio-Rad), or ProcartaPlex Th1/Th2/Th9/Th17/Th22/Treg Cytokine 17-Plex Mouse Panel (EPX170-26087-901) (Thermo Fisher Scientific). Antibody subclasses were measured using ProcartaPlex Mouse Antibody Isotyping 7-plex panel (EPX070-20815-901). In all cases the analyses were carried out following the manufacturers' instructions, using a Luminex 200 reader and BioPlex Manager 6.0 software (BioRad). Analysis was performed on fluorescence index (FI) values minus background, while figures show concentrations calculated from standard curve. Analytes with more than $40 \%$ data points below limit of detection (Antweiler, 2015) were excluded from statistical evaluation.

\section{Statistical Analyses}

Microbial profiles and composition were analyzed in the $\mathrm{R}$ programming environment ( $\mathrm{R}$ version 4.0.2) (R_Core_Team, 2020) using Rhea (Lagkouvardos et al., 2017) ${ }^{1}$. To account for differences in sequence depth, OTU tables were first normalized by dividing each sample's reads to their total reads, then multiplication by the total reads of the smallest sample. Betadiversity was calculated based on generalized UniFrac distances (Chen et al., 2012) and the significance of separation between groups was tested by permutational multivariate analysis of variance (PERMANOVA). Alpha-diversity was assessed based on species richness and Shannon effective diversity as described in detail in Rhea. Only taxa with a prevalence of $\geq 30 \%$ (proportion of samples positive for the given taxa) in one given group, and relative abundance $\geq 0.25 \%$ were considered for statistical testing. For analyses of differences in relative abundance between $>2$ groups (Exp. 2), Kruskal-Wallis Rank Sum test was performed. A significant Kruskal-Wallis test $(p<0.05)$ was followed by pairwise Wilcoxon Rank Sum tests. $P$-values were corrected for multiple comparisons according to the Benjamini-Hochberg method, and adjusted $p$-values are reported. For comparisons of two groups (Exp. 3), Wilcoxon Rank Sum tests were performed directly. For analyses of differences in prevalence between groups, Fisher's exact tests were performed. Over-time analyses within groups were performed using paired Wilcoxon Signed Rank Sum tests.

In order to identify patterns of differentially abundant and prevalent OTUs in Feral and SPF mice, we conducted an indicator species analysis implemented by the indicspecies package (De Cáceres and Legendre, 2009) in R. The significance of the associations was determined by permutation tests followed by Benjamini-Hochberg correction of resulting $p$-values. To identify highly indicative OTUs, we included only OTUs that occurred in $\geq 70 \%$ of the mice in either the Feral or SPF group at each timepoint. For Exp. 3, an indicator species analysis was conducted in the same manner as described for Exp. 2, to identify OTUs indicative of Chow-fed or Seed-fed animals independent of timepoint. For all groups at both timepoints, the relative abundances of the identified indicator-OTUs were plotted with the heatmap. 2 function from the gplots package (Warnes et al., 2020 ) in $\mathrm{R}$. The closest species related to the indicator-OTU sequences were identified with EzBioCloud (Yoon et al., 2017). See Supplementary Table S3 for a complete list of indicatorOTUs presented in Figure 3E and Supplementary Figure S4E.

Immunological data was analyzed using log (Ln)-transformed values. Comparisons between groups were performed using the statistical applications JMP v.14 (SAS Institute Inc.) or Prism v.7 (GraphPad Software, Inc.), applying Student's $t$-test for two groups, and Tukey-Kramer's multiple comparison test for $>2$ groups, at alpha level 0.05, unless otherwise stated. In figures with letter indications, levels not sharing the same letter were significantly different. Multivariate analyses were

\footnotetext{
${ }^{1}$ https://github.com/Lagkouvardos/Rhea
} 
A

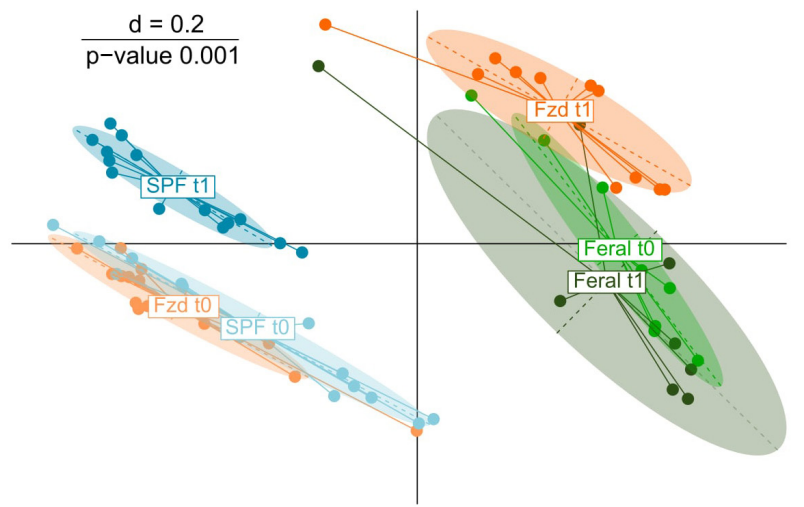

C

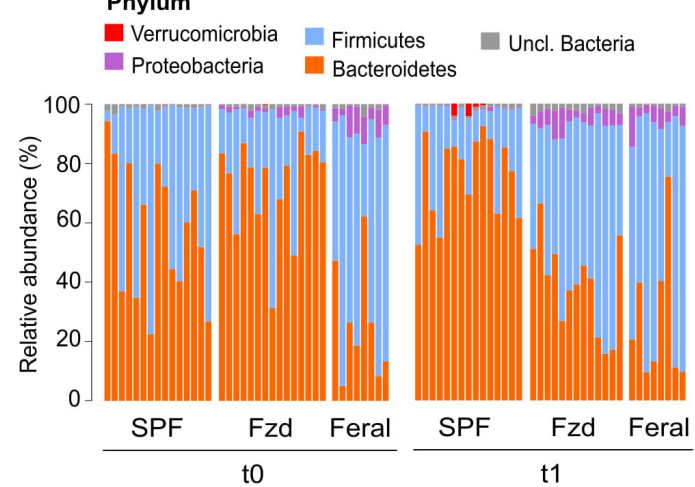

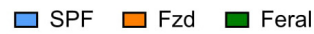
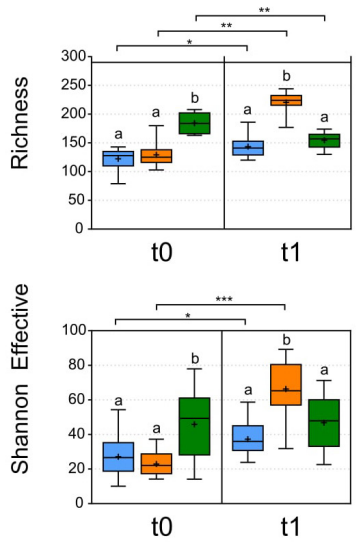

D
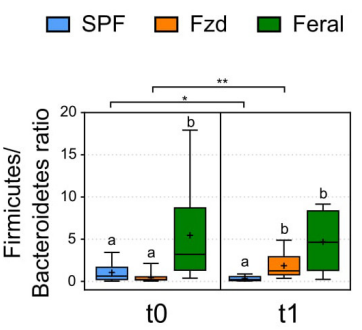

E

Relative abundance (\%)
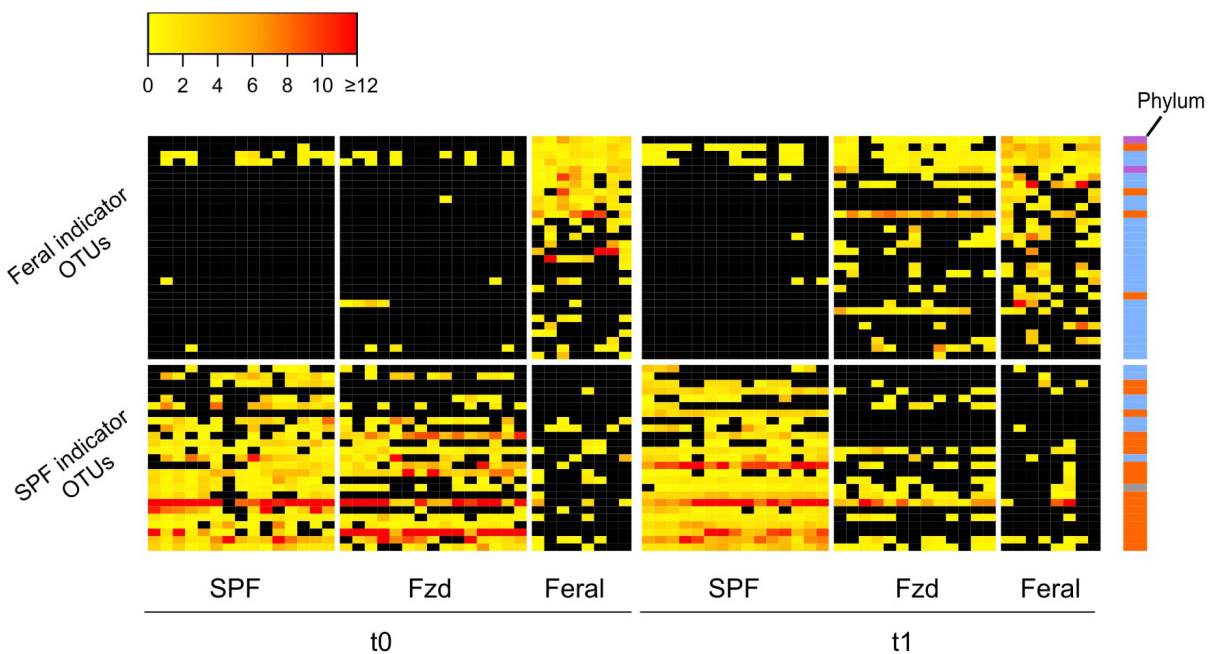

FIGURE 3 | Feralization lead to a gut microbiota diversity and composition converging with feral mice. Presented data is from Exp. 2. (A) Multi-dimensional scaling (MDS) plot of microbiota profiles for feral, feralized (Fzd) and SPF mice at baseline (t0) and termination ( $\mathrm{t} 1)$. Similarities between profiles were computed using generalized Unifrac distances. The significance of separation between groups was tested by PERMANOVA. $d$ = dissimilarity scale. (B) Richness (observed OTUs) and Shannon effective diversity index. Box plots show median (line), mean (+), IQR (box) and minimum to maximum (whiskers). Asterisks designate over-time differences determined by Wilcoxon Signed-Rank Sum test. Differences between groups at each timepoint were determined by Kruskal-Wallis and Mann-Whitney $U$-tests. The Benjamini-Hochberg method was used to correct for multiple testing. Levels not sharing the same letter were significantly different at $\alpha=0.05$. ${ }^{*} p \leq 0.05,{ }^{* *} p \leq 0.01,{ }^{* * *} p \leq 0.001$. (C) Taxonomic binning at the rank of phylum, presented as relative abundance for each individual, with groups and timepoints indicated. (D) Firmicutes/Bacteroidetes ratio presented as in (B). (E) Heatmap of relative abundance of Feral- and SPF-associated OTUs identified by indicator species analysis. Phyla of which the OTUs belong to are designated with colored squares specified in (C). Relative abundances of the OTUs $<0.25 \%$ were set to NA (black). All plots: $n=8$ (feral) or $n=13-15$ (other groups). 
performed using the principal component analysis (PCA) on Correlations, and hierarchical clustering using Ward's minimum variance method in JMP on the variables listed in Supplementary Table S4, excluding one Fzd mouse with an incomplete data set.

\section{RESULTS}

\section{Lab Mice Adapted Well to a Farmyard Habitat in the Presence of Feral Mice}

Throughout Exp. 1 we closely monitored how animals performed through direct inspection and using surveillance or handheld cameras (Supplementary Figure S2). Feral and B6 mice were released simultaneously into the pens to avoid biased territorializing (Supplementary Video S2). The mice dug holes in the soil that appeared preferential for nesting rather than using wooden houses provided for this purpose (Supplementary Video S3). Feral and B6 mice mingled well, in both the male-female and the female-female setups. Feral mice generally reacted to human presence by hiding, re-emerged within few minutes and approached people (Supplementary Video S4), whilst the B6 mice were generally less shy. Feral mice quickly adapted to drinking from water bottles. However, four feral individuals were found dead with no visible signs of injuries and lack of water being a possible cause. No B6 mice died, showed visible bruises or signs of disease, except one slow-moving $\mathrm{Fzd}^{\mathrm{M}}$ female that was excluded from the study. $\mathrm{Fzd}^{\mathrm{M}}$ females mated with feral males and produced litters that were cared for in a shared dirt-hole nursing colony. However, since past or present pregnancy might confound the readouts, we chose to carry out subsequent experiments in an all-female setting. In Exp. 2 the observed behavior was similar to Exp. 1, and all introduced mice were recaptured in healthy condition.

\section{Feralized Mice Acquired Mouse Pathogens and a Feral-Like Gut Microbiota}

Serum samples from four individuals of each mouse group in Exp. 1 were screened for antibodies against a range of pathogens. Feral mice carried antibodies for Minute virus of mice (MVM), Mouse parvovirus (MPV), Mouse Cytomegalovirus (MCMV) and, in one case, Pasteurella pneumotropica (Pp) (Supplementary Table S5A). Fzd ${ }^{\mathrm{M}}$ mostly seroconverted to mimic the feral mice, while only a single $\mathrm{Fzd}^{\mathrm{F}}$ mouse tested positive for one pathogen $(P p)$. SPF controls were negative for all tested agents. A gross parasitological examination of intestines with fecal content revealed the presence worms or eggs in feral and $\mathrm{Fzd}^{\mathrm{M}}$ mice, but to a less extent in $\mathrm{Fzd}^{\mathrm{F}}$ mice while negative in SPF controls (Supplementary Table S5B).

The terminal gut microbiota in stool samples from $\mathrm{Fzd}^{\mathrm{F}}$ mice in Exp. 1 has been reported previous (Lindner et al., 2015). Briefly, the microbiota profile of the feralized mice approached that of feral mice, including a higher relative abundance of Firmicutes and Proteobacteria, while SPF mice stood out with a separate profile. Data from Exp. 2 largely mirrored the findings of Exp. 1. At baseline, beta-diversity analysis demonstrated a distinct clustering of baseline gut microbiota of the B6 mice separate from feral mice (Figure 3A), and alpha-diversity measures showed a significantly higher number of observed OTUs (richness) in feral mice compared to the Fzd and SPF groups (both $p \leq 0.001$ ) (Figure 3B). At the rank of phylum, a significantly higher relative abundance of Firmicutes and lower relative abundance of Bacteroidetes was detected in feral mice compared to Fzd (both $p \leq 0.001$ ) and SPF ( $p=0.035$ and $p=0.005$, respectively), as reflected in a higher Firmicutes/Bacteroidetes ratio (Figures 3C,D). Moreover, Proteobacteria abundance above cutoffs were detected in all feral mice and the majority of feralized mice, but only in one SPF individual (Figure 3C). In feral mice, the Proteobacteria was mainly accounted for by two OTUs with closest sequence similarity to Helicobacter species (Helicobacter ganmani, 99.6\% similarity; Helicobater typhlonius, $100 \%$ similarity), while in Fzd the Proteobacteria was mainly accounted for by one OTU with the closest sequence similarity to Kiloniella laminariae ( $86.3 \%$ similarity).

A clear shift in the microbiota profile was seen following feralization, in which the Fzd mice approached a Feral-like profile (Figure 3A). Feralization led to a dramatic increase in both richness and Shannon effective $(p=0.002$ and $p \leq 0.001$, respectively), indicating an elevated number of species representing a higher level of phylogenetic diversity (Figure 3B). An increase in relative abundance of Firmicutes and decrease in relative abundance of Bacteroidetes (both $p=0.001$ ) was observed following feralization, reflected in an increased Firmicutes/Bacteroidetes ratio $(p=0.005)$ (Figures 3C,D). The shift following feralization was further supported by analysis of the terminal gut microbiota, in which the Fzd and feral mice demonstrated significantly higher alpha-diversity measures and Firmicutes/Bacteroidetes ratios, and increased relative abundances of Proteobacteria compared to the SPF mice (Figures 3C,D). Moreover, we conducted an Indicator Species Analysis to identify OTUs that were most indicative for Feral and SPF mice based on the probability of occurrence and abundance in these groups independent of timepoint. This algorithm was first developed by Dufrene and Legendre (1997) and has been employed previously to track persistence of OTUs in mice following environmental changes (Seedorf et al., 2014) and fecal microbiota transfer from wild to laboratory mice (Rosshart et al., 2017). Generally, the OTUs associated with Feral mice belonged to the Firmicutes phylum, while the SPF-associated OTUs were members of Bacteroidetes, mirroring the detected phylumlevel differences (Figure 3E). Two OTUs with closest sequence similarities to Helicobacter species (Helicobacter ganmani, 99.6\%; Helicobater typhlonius, 100\%) were identified as Feral-associated OTUs (Figure 3E and Supplementary Table S3A). By plotting the abundances of the indicator OTUs for all samples, we were able to track the Feral-associated and SPF-associated OTUs in the Fzd group over time. Prior to feralization, the Fzd and SPF groups showed overlapping patterns, with high abundance of SPF-associated and generally low abundance of Feral-associated OTUs. Following feralization, a substantial proportion of Feral-associated OTUs was detected, while only a very few SPF-associated OTUs undetected in Feral mice remained in the Fzd group at endpoint (Figure 3E). 
Taken together, feralization led to a substantial change in gut microbiota structure, approaching the profile and composition seen in feral mice. Seropositivity to viral pathogens was detected in all feral mice, and in female feralized mice co-housed with feral males, but not in those co-housed with feral females.

\section{Feralization Lead to Immunophenotypes Consistent With Antigenic Experience and Immune Training}

Cellular phenotypes were measured according to gating strategies shown in Supplementary Figure S1. In both Exp. 2 and Exp. 3, the number of T-cells and $\mathrm{CD}^{+}$and $\mathrm{CD}^{+}$subsets were similar in feralized and SPF mice in SPL as well as peripheral lymph nodes (PLNs) (not shown). Memory T-cells, defined as $\mathrm{CD}_{4}{ }^{+} \mathrm{CD}_{2} \mathrm{~L}^{+}$central memory $(\mathrm{CM})$ cells, or CD $44^{+} \mathrm{CD} 2 \mathrm{~L}^{-}$effector memory (EM) cells were measured in the spleen and PLNs, respectively, according to the most common compartments for these subsets (Wherry et al., 2003; Stockinger et al., 2006). Feralized mice showed increased levels of $\mathrm{CD}^{+}$ $\mathrm{T}$ cells with an EM phenotype in the spleen (Figures $4 \mathrm{~A}, \mathrm{~B}$ ) as well as CM cells in the PLNs (Figures 4C,D). A tendency for increased proportions of $\mathrm{EM} \mathrm{CD} 4^{+}$cells was seen in the spleen of feralized mice (Figures 4E,F), but not for $\mathrm{CM} \mathrm{CD} 4^{+}$cells in the PLNs (Figures 4G,H). Feral mice consistently had more cells displaying an EM or CM phenotype within the CD8 as well as the CD4 subsets (Figures $\mathbf{4 A - H}$ ). To assess if T-cells of feralized mice had changed their potency as effector cells, we cultured splenocytes with anti-CD3/CD28 coupled beads for $48 \mathrm{~h}$ in the presence of IL-2 in Exp. 2. The frequency of interferon-gamma positive $\mathrm{CD}^{+}{ }^{+}$and to a lesser extent $\mathrm{CD} 4^{+} \mathrm{T}$-cell populations was higher in feralized mice compared to SPF mice (Figures 5A,B).

Regulatory T-cells (Tregs) $\left(\mathrm{CD} 3{ }^{+} \mathrm{CD} 4{ }^{+} \mathrm{CD} 25^{+}\right.$Foxp $\left.^{+}\right)$were measured in PLNs. In Exp. 1, feralized mice had similar number of Tregs as SPF mice, while feral mice had a lower proportion (Figure 6A). In Exp. 2, slightly elevated Treg numbers were seen in feralized but not in feral mice (Figure 6B). We furthermore, assessed neuropilin-1 (NRP-1) dim or negative cells, associated with peripherally induced regulatory T-cells (pTregs), especially induced by gastrointestinal exposure (Bilate and Lafaille, 2012). In both Exp. 1 and 2, the proportion of pTregs was slightly elevated in the feral mice, but insignificantly so in feralized mice (Figures 6C,D).

NK cells numbers were elevated in PLNs but not spleens of feral mice (Figures 7A,B and Supplementary Figures S3A,B), as observed previously (Boysen et al., 2011). In feralized mice NK cells tended to increase, albeit not statistically significant, in the PLNs (Figures 7A,B), while no differences were observed

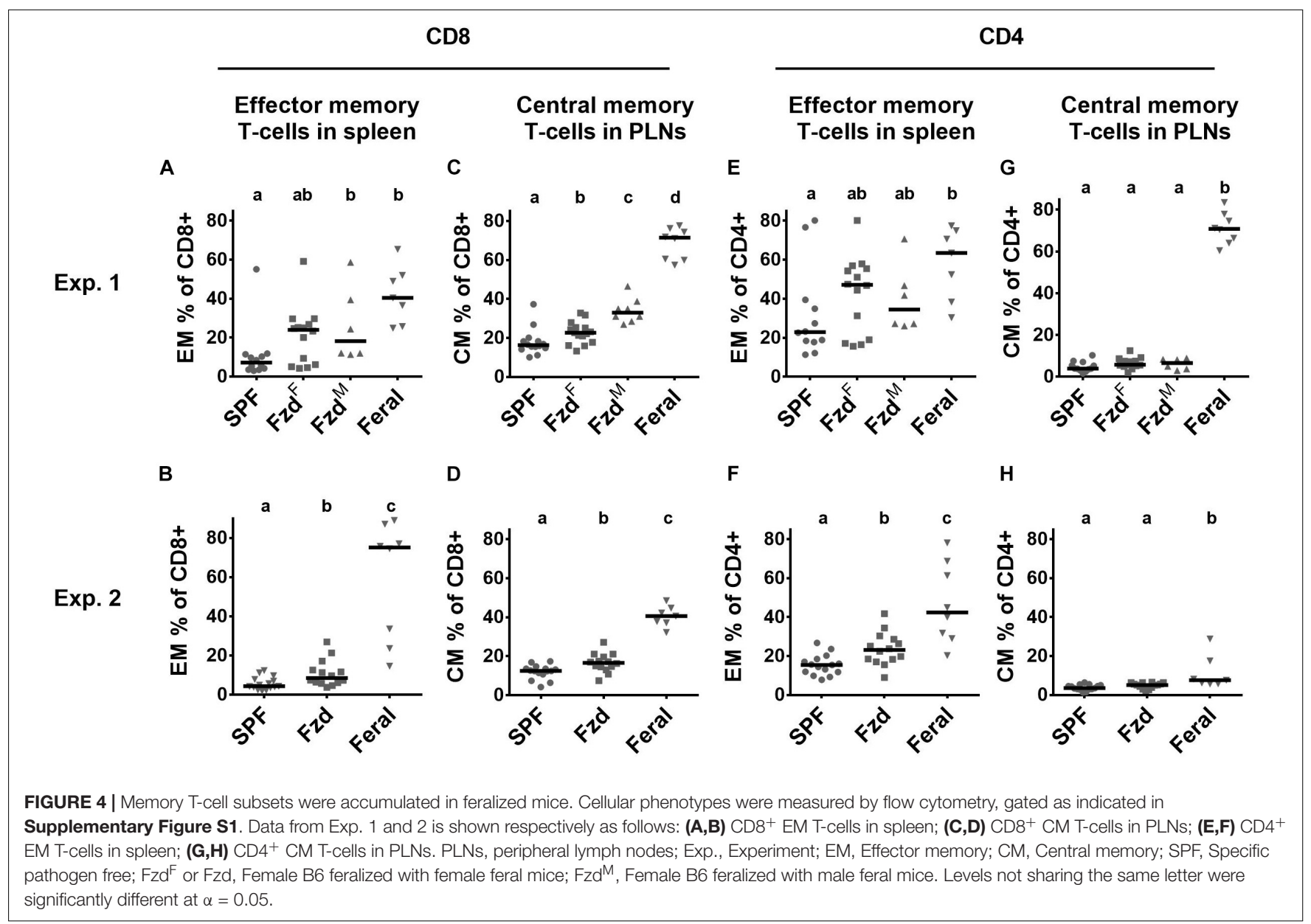




\section{CD4+}

A

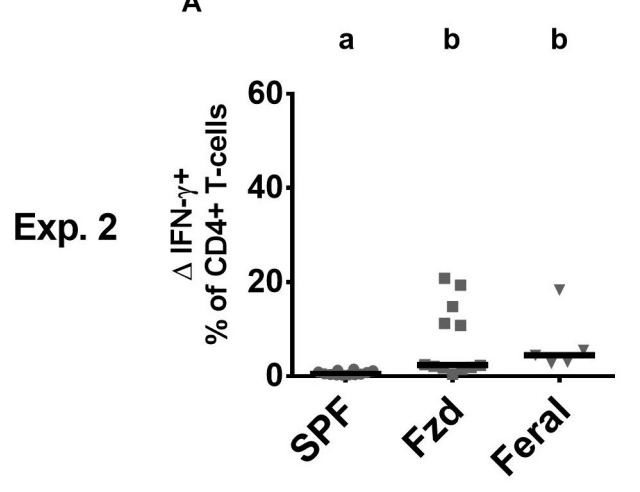

\section{CD8+}

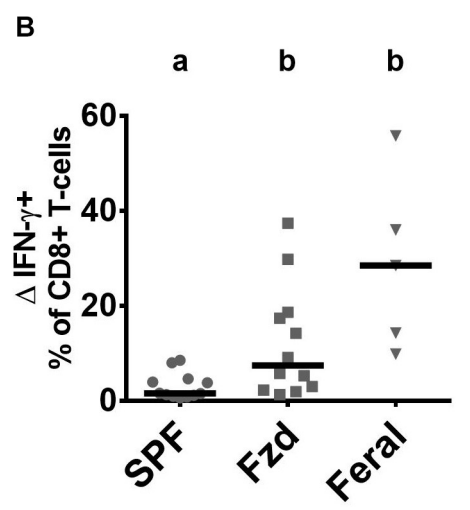

FIGURE 5 | T-cells in feralized mice responded to in vitro stimulation with increased interferon gamma (IFN- $\gamma$ ) production. Splenocytes were incubated for $48 \mathrm{~h}$ with bead-coupled anti-CD3/CD28 antibodies in the presence of IL-2 and measured for intracellular IFN- $\gamma$ production by flow cytometry. $\Delta$ IFN- $\gamma^{+}$(IFN- $\gamma^{+}$NK cells in stimulated cultures - ditto in medium control cultures) is shown as per cent of CD4 ${ }^{+}$T-cells (A) or of CD8 ${ }^{+}$T-cells (B). All data from Exp. 2 . Abbreviations and statistics as in Figure 4.

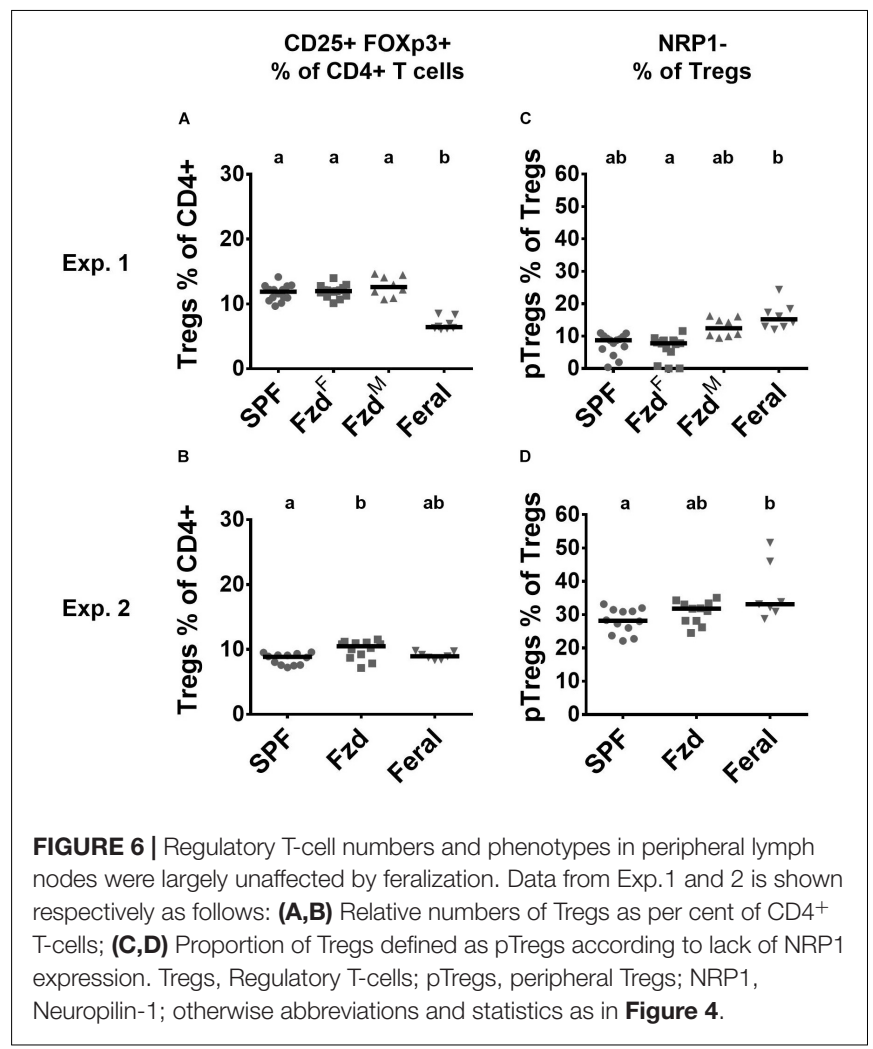

in the spleen (Supplementary Figures S3A,B). Murine NK cells can be phenotypically divided into maturation stages as early (S1) $\mathrm{CD}_{27}^{-} \mathrm{CD}_{11 b^{-}}$, mid (S2) $\mathrm{CD} 27^{+} \mathrm{CD}_{11 \mathrm{~b}}{ }^{-}$, late (S3) $\mathrm{CD}_{27}{ }^{+} \mathrm{CD} 11 \mathrm{~b}^{+}$, and fully mature (S4) $\mathrm{CD} 27^{-} \mathrm{CD} 11 \mathrm{~b}^{+}$stages (Chiossone et al., 2009; Abolins et al., 2017), most cells normally found within the S2-S4 categories. We found that feral mice had a decreased S4/S2 ratio in both PLNs and in spleen, as seen previously (Boysen et al., 2011). In contrast, increased S4/S2 ratio was detected in feralized mice, most evident in the PLNs (Figures 7C,D and Supplementary Figures S3C,D). KLRG1 expression was elevated in NK cells in feral mice in PLN (Figures 7E,F) and partly in spleen (Supplementary Figures S3E,F), confirming previous observations (Boysen et al., 2011). To a lesser extent, feralized mice also had elevated KLRG1 in PLNs (Figures 7E,F), a tendency also evident in spleen (Supplementary Figures S3E,F).

Most tested serum cytokines were low and not significantly altered between groups (Figure 8). However, IL-18 was lower in the feralized and feral mice (Figure 8F). A tendency of increased TGF- $\beta 1$ in feralized mice was noted but with high variability and not statistically confirmed (Figures 8G,H). Some additional cytokines were either not significantly altered or fell below the lower limit of detection (Supplementary Table S6).

Increased serum levels of IgE and IgG1 have previously been reported in feral mice (Devalapalli et al., 2006; Abolins et al., 2011), and in Exp. 2 we measured immunoglobulin subclasses using a multiplex assay, demonstrating that feral mice had increased serum IgA, IgE, Ig2a, Ig2b, and IgM (Figure 9). Feralized mice showed a tendency of increased IgE and IgG2b, while the remaining subclasses fell within the same range as SPF controls. IgG1 was not detected above background levels (not shown).

The data from Exp. 2 had a completeness that allowed multivariate analysis of immune parameters, in order to explore any co-variation undetected when assessing single parameters. A PCA analysis revealed that feralized mice grouped separately from SPF controls, in the direction of feral mice (Figure 10A), significantly different between all groups in first principal component (Prin1) but not Prin2 (Figure 10B). Likewise, a cluster analysis grouped mice from each study group separately, except a minor overlap between SPF and feralized mice (Figure 10C). 


\section{NK cells}

A

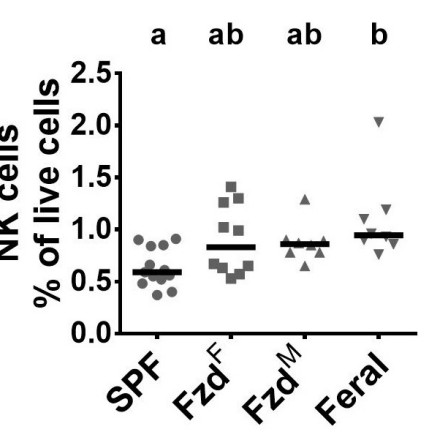

B

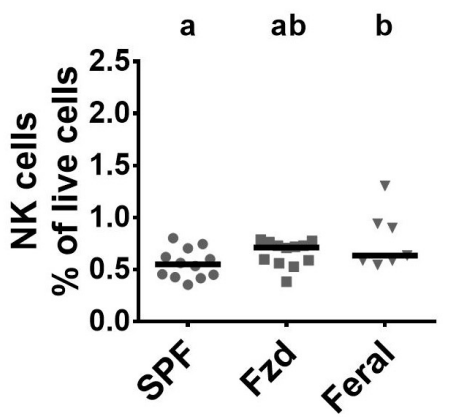

\section{Subset ratio among NK cells}

\section{KLRG1+ of NK cells}

C

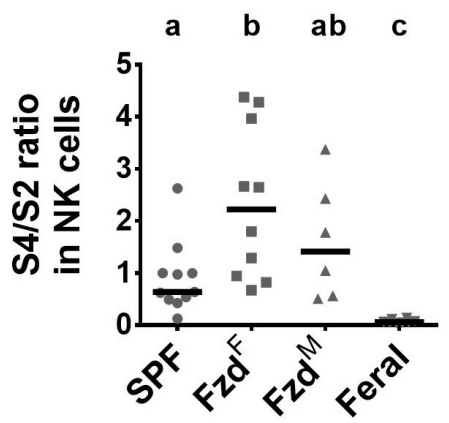

D

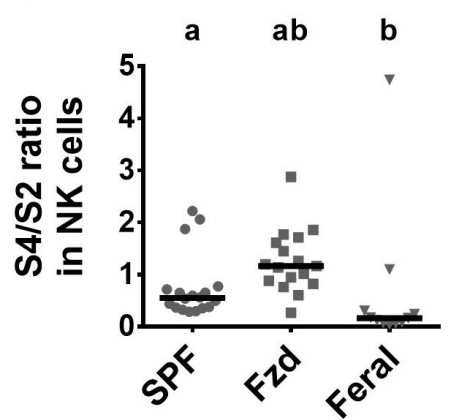

E

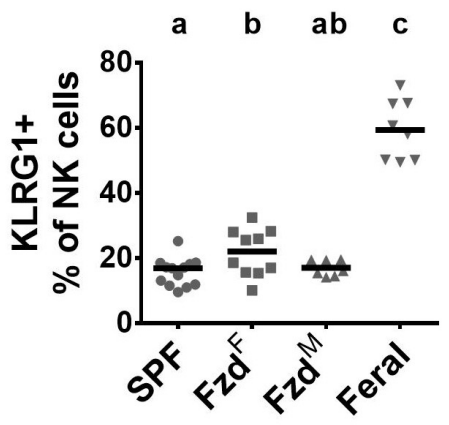

F

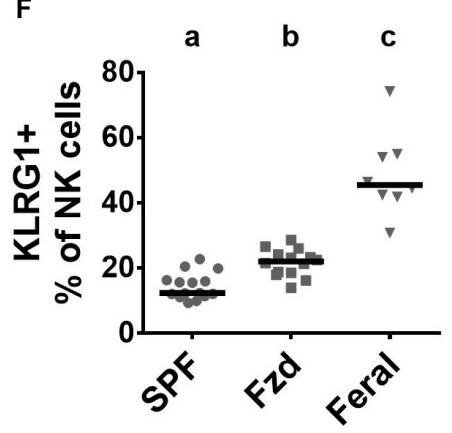

FIGURE 7 | Natural killer (NK) cells in feralized mice showed signs of maturation. Maturational subsets were defined as shown in Supplementary Figure S1, with subset ratio calculated based on $\mathrm{CD} 27^{+} \mathrm{CD} 11 \mathrm{~b}^{-}(\mathrm{S} 4) / \mathrm{CD} 27^{-} \mathrm{CD} 11 \mathrm{~b}^{+}$(S2). Data from Exp.1 and 2 is shown respectively as follows: (A,B) Relative numbers of NK cells as per cent of live cells; (C,D) Ratio of S1/S2 subsets of NK cells within NK cells; (E,F) Proportion of NK cells expressing KLRG1. Abbreviations and statistics as in Figure 4.

\section{Diet May Explain Shifts in Gut Microbiota, but Was Not Found to Drive Immunological Changes}

To assess the contributions of differing diets between groups in Exp. 1 and 2 to gut microbiota and immunophenotypes, Exp. 3 was designed to incorporate the two diets in a SPF lab cage setting. Microbial profiling of feces showed a shift in microbiota composition and increased alpha-diversity measures on both diets, although more prominently in mice fed the seed diet compared to regular chow (Supplementary Figures S4A,B). At the rank of phylum, no significant changes were detected in the chow-fed animals. For the seed-fed animals, we detected a significantly decreased relative abundance of Bacteroidetes $(p=0.013)$ and increased relative abundance of Firmicutes $(p=0,011)$, reflected in increased Firmicutes/Bacteroidetes ratio over-time $(p=0.048)$ (Supplementary Figures S4C,D). Similar to Exp. 2, the over-time changes were supported by analyses of the terminal gut microbiota, in which seedfed mice demonstrated significantly higher alpha-diversity measures and Firmicutes/Bacteroidetes ratio compared to the chow-fed mice. However, in contrast to the findings from
Exp. 2, relative abundances of Proteobacteria were unchanged following the different diets. In the analysis of data from Exp. 3 we also conducted an indicator species analysis to identify OTUs that were most indicative for the Chow-fed and Seedfed mice independent of timepoint. Relatively few indicatorOTUs were identified in this analysis, indicating only small differences between Chow- and Seed-fed mice at the OTU-level (Supplementary Figure S4E and Supplementary Table S3B). At baseline, prior to administration of different diets, the two groups showed overlapping patterns (Supplementary Figure S4E). From baseline to endpoint, Seed-fed animals showed an enrichment of several OTUs belonging to the phylum Firmicutes, mirroring the findings at phylum-level. Whilst we found changes in gut microbiota following the two diets, immunophenotyping showed no diet-induced difference in $\mathrm{CD} 44^{+}$cells in the $\mathrm{CD}^{+}$ $\mathrm{T}$-cell compartment. In the $\mathrm{CD} 4^{+} \mathrm{T}$-cell subset, a minor increase of $\mathrm{CD}_{4} 4^{+}$cells was observed in seed-fed mice (Supplementary Figure S5A). In ex vivo CD3/CD28 stimulated splenocytes, intracellular IFN-g production was similar in the two diet groups in both $\mathrm{CD}^{+}$or $\mathrm{CD}^{+}{ }^{+}$T-cells (Supplementary Figure S5D). Moreover, we observed no significant effect of diet on Treg 
IL-5

A

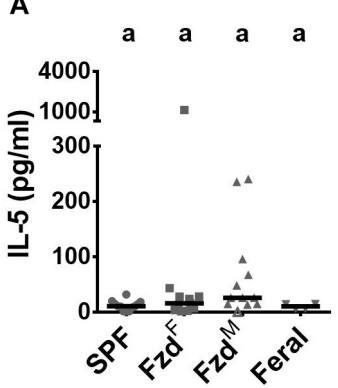

B

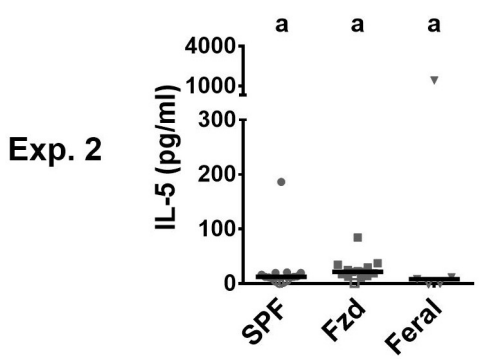

IL-6

C

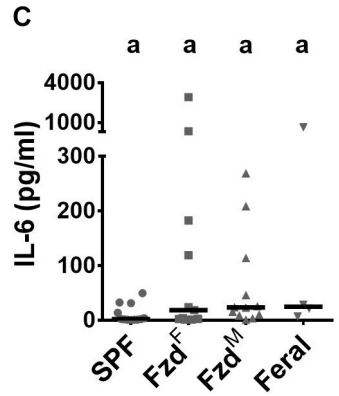

D

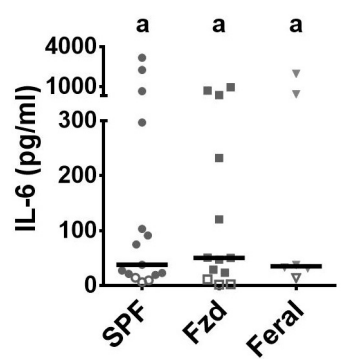

IL-18

E

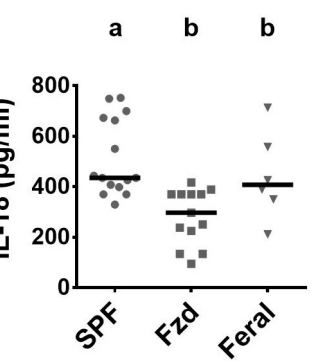

TGF- $\beta 1$

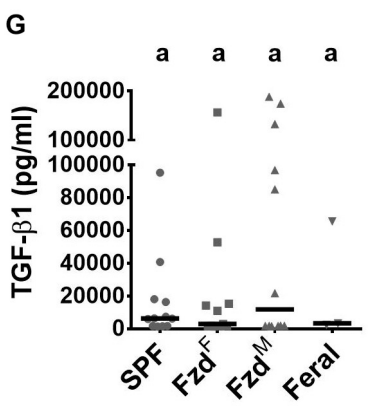

H

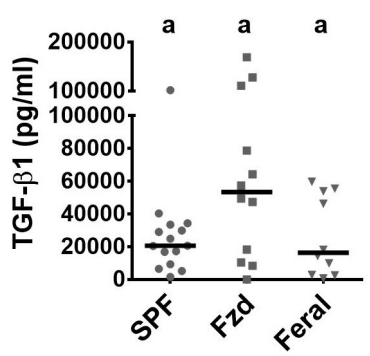

FIGURE 8 | Cytokines in serum were minimally affected by feralization. Serum samples were measured by multiplex assays. Data from Exp. 1 and 2 is shown respectively as follows: (A,B) IL-5; (C,D) IL-6; (E,F) IL-18; (G,H) TGF- $\beta$. Open symbols indicate measurements below accurate quantification. N.D., No data. Otherwise abbreviations and statistics as in Figure 4.

levels or pTreg proportions, NK cells or NK cells subsets (Supplementary Figures S5B,D).

Taken together, the findings from Exp. 3 indicated that a diet similar to that given to feralized mice in Exp. 1 and 2 caused a significant shift in gut microbiota structure, yet provided no evidence for any shift in immunological parameters assignable to the diet.

\section{DISCUSSION}

A spacious and naturalistically enriched environment meets an increasing demand to improve housing conditions to refine the experimental output from mouse models (Balcombe, 2010). Large indoor enclosures have previously been used to study house mouse behavior (Gray et al., 2000; Jensen et al., 2003, 2005; Weissbrod et al., 2013), but to our knowledge, no reports describe the microbiological and immunological phenotypes of mice reared in such enclosures enriched as a naturalistic environment. The tremendous adaptability of the house mouse implies that no single habitat is universally "natural." Nevertheless, house mice are predominantly found in or near human dwellings, farm buildings, food stores and waste areas, and its dispersal largely follows human movements (Pocock et al., 2005). The house mouse often forms high-density territories as small as a few square meters (Selander, 1970). To set up a well-defined naturalistic scenario we constructed large pens containing essential farmyard elements through domestic animal fecal material, soil and plants, and with wild-caught mice present as microbial donors. The aim of the current report was to observe the performance of laboratory mice housed in this model system and to observe their resulting fecal microbiota and key elements of their systemic immunity phenotype.

Feralization led to a significant shift in gut microbiota composition and increased alpha-diversity measures following feralization, supportive of previous reports of microbially exposed mice (Ottman et al., 2019; Liddicoat et al., 2020). We observed an enrichment of Proteobacteria in feral and feralized mice, in agreement with findings in "wildling" B6 mice born to feral mothers (Rosshart et al., 2019) as well as B6 mice co-housed with pet store mice (Huggins et al., 2019). Two OTUs associated with feral mice microbiota showed the closest similarity to Helicobacter species and were enriched in feralized mice. In a recent paper, Helicobacter species have been suggested to trigger colonic $\mathrm{T}$ cell responses in a context-dependent manner (Chai et al., 2017). Moreover, the higher Firmicutes/Bacteroidetes ratios in feralized and feral mice corresponds to a previous report of feral mice (Kreisinger et al., 2014), but contrasts the lower relative abundance of Firmicutes seen in fecal samples from wildlings (Rosshart et al., 2019), from B6 mice receiving fecal transfer from wild mice (Rosshart et al., 2017), as well as from soilexposed mice (Ottman et al., 2019). However, care should be taken when interpreting between studies, as geographical factors have been shown to drive the microbiota composition to a larger extent than genotypes, including between Mus musculus subspecies (Linnenbrink et al., 2013; Kreisinger et al., 2014). 


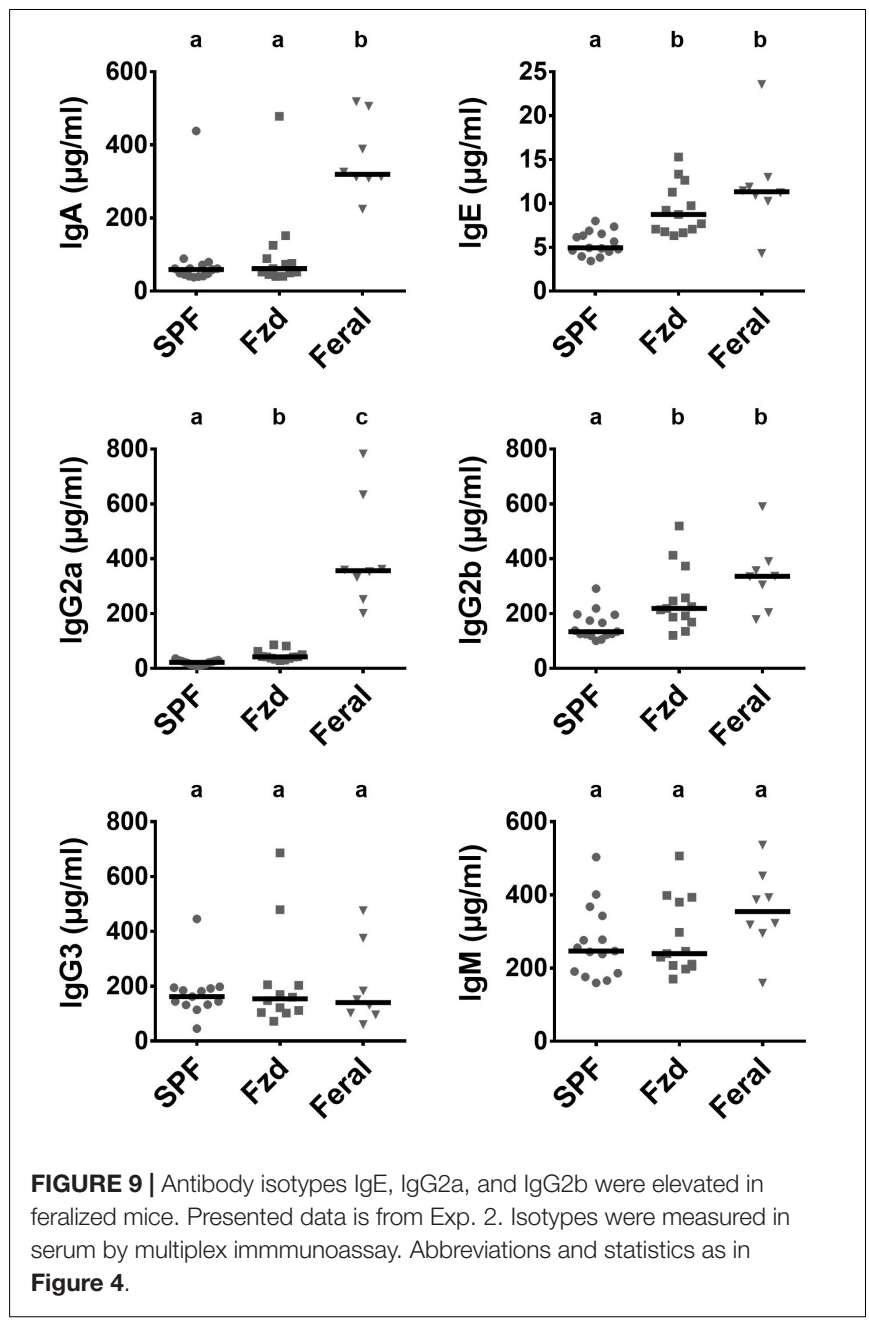

Notably, feral mice maintained a similar microbiota before and after pen housing in Exp. 2. Their prior microbial environment and diet is unknown, but they were caught at farms distant from the sources used for enrichment, and these findings could either indicate that the conditions we created reflected their feral situation, or that their colonized microbiota was more resilient to change compared to the SPF-derived laboratory mice.

The seed-based diet offered in the naturalistic environment contained higher amounts of fiber and fat compared to the standard chow diet, both of which are groups of dietary components demonstrated to alter gut microbiota composition and influence immunity in a wide range of previous studies (Daniel et al., 2014; Trompette et al., 2014; Desai et al., 2016; Xiao et al., 2017; Las Heras et al., 2019). We therefore set up a third experiment to assess this impact in an otherwise hygienic context. Seed-fed mice had increased alpha-diversity and Firmicutes/Bacteroidetes ratio, suggesting a partial explanation for changes seen in the feralized mice. We did not observe differences in the investigated immune parameters following the two diets, suggesting the alterations of immunophenotypes were driven by other stimuli, or other components of the microbiota, than those conferred by diet.
A multivariate analysis showed that the combined systemic immune phenotype of feralized mice clustered distinctly from SPF mice in the direction of feral mice, albeit still closer to SPFs. For cellular measurements we concentrated on NK and T-cell phenotypes associated with maturation and memory. Feralized and feral mice had increased numbers of memory CD8+ T cells, in line with report of long-lasting expansion following in vivo challenge (Vezys et al., 2009). Similar upregulation of memory $\mathrm{T}$ cells has been reported in feral and pet-store mice, in lab mice co-housed with pet-store mice and in rewilded mice (Beura et al., 2016; Abolins et al., 2017; Lin et al., 2020). Following ex vivo stimulation, we found that T-cells in feralized and feral mice responded more potently with IFN-gamma production compared to lab mice, similar to previous reports in feral and rewilded mice (Abolins et al., 2017; Lin et al., 2020).

We found little effect of feralization on the total Treg cell numbers, while pTregs, defined as NRP-1 ${ }^{-}$Tregs (Bilate and Lafaille, 2012), showed a slightly increasing tendency, not significant in feralized but significant in feral mice. A previous study in feral mice found marginal increase in splenic Tregs (Abolins et al., 2017), while two other studies of microbially diversified lab mice found no alteration in Treg cell numbers (Frossard et al., 2017; Rosshart et al., 2019). These findings suggest that Tregs in systemic organs do not respond substantially to these types of environmental triggers.

NK cells may be activated by pathogens or primed by proinflammatory cytokines, transforming the cells into a more mature state, in many cases persisting as memory-like or trained NK cells (Nabekura and Lanier, 2016; Netea et al., 2020). In mice, trained NK cells have been found to display a mature KLRG1 ${ }^{+}$ and $\mathrm{CD} 27^{-} \mathrm{CD}_{11 b^{+}}$phenotype (Nabekura and Lanier, 2016). We reproducibly found more $\mathrm{CD} 27^{-} \mathrm{CD} 11 \mathrm{~b}^{+}$and KLRG1 ${ }^{+}$ NK cells in feralized B6 mice. Notably, as reported previously (Boysen et al., 2011; Abolins et al., 2017), feral mice had a contrasting overweight of $\mathrm{CD}_{2} 7^{+} \mathrm{CD} 11 \mathrm{~b}^{-} \mathrm{NK}$ cells, yet with a high KLRG1 expression. Feral and feralized mice underwent the same microbial pressure for 2-3 months, suggesting that the $\mathrm{CD} 27 / \mathrm{CD} 11 \mathrm{~b}$ discrepancy may be genetic rather than environmental. However, this aberrance is unlikely due to genetic differences amongst subspecies, as while the present mice were M. m. musculus-dominated, the same NK cell phenotype have been noted in feral M. m. domesticus mice (Abolins et al., 2017), the latter constituting the major genetic background for the B6 mouse (Yang et al., 2011). Regardless of cause, the finding emphasizes the importance of assessing genetically controlled individuals in this type of studies.

Low levels of serum cytokines were detected and these were apparently not sensitive to environmental changes, as also seen in wildlings (Rosshart et al., 2019). The observed elevation of IgE in feral and feralized mice compare with findings from other studies (Devalapalli et al., 2006; Abolins et al., 2011, 2017) and are possibly caused by the presence of parasites as were detected in Exp. 1. Besides parasites, seroconversion for pathobionts were especially evident in the $\mathrm{Fzd}^{\mathrm{M}}$ females, which made frequent intimate contacts with feral males during mating. In the all-female setup, a feral-type feral microbiota was obtained, 
C
A

A

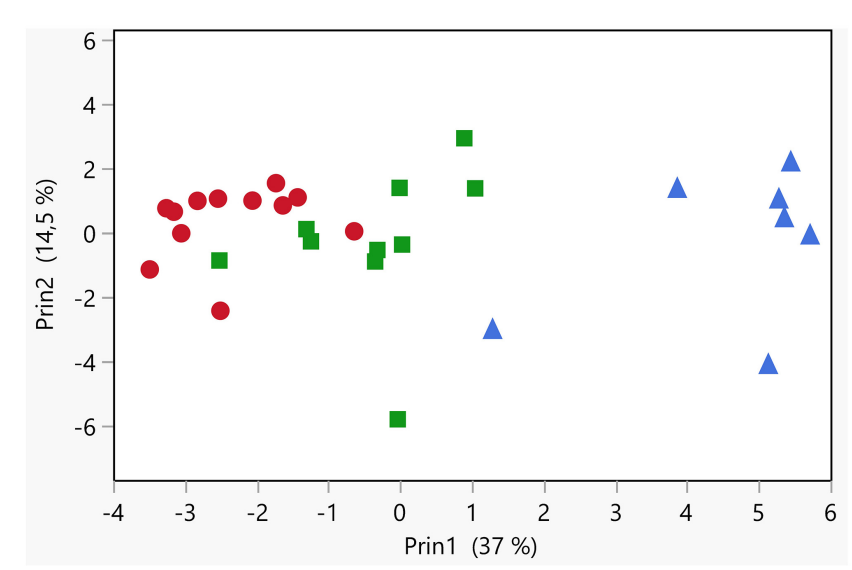

B

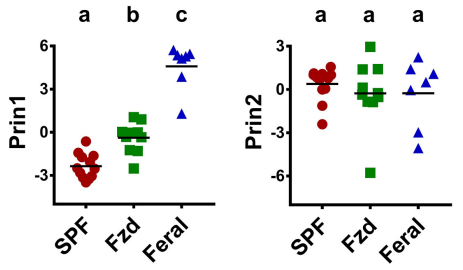

FIGURE 10 | Multivariate analyses of immune parameters showed that feralized mice clustered in the direction of feral mice. Presented data is from Exp. 2. (A) Principal coordinate analysis of Ln transformed values of variables listed in Supplementary Table S3. (B) Post-PCA analysis of the two first PCA variables (Prin1 and Prin2) using Tukey-Kramer's multiple comparison for all groups. Different letters designate statistical significance with alpha level 0.05. (C) Hierarchical cluster analysis, numbers refer to individual mouse IDs. Fzd = Female B6 feralized with female feral mice. yet the serological results indicated that they acquired less of a pathogenic burden. These findings may suggest that relatively strong and/or frequent transmission pressure of pathobionts is needed for a mouse to reach a feral-like immunophenotype.

The scope of the presented studies was to achieve a full-scale naturalistic environment, rather than to explore underlying mechanisms, which would require multiple investigations or a substantial reduction of the very elements that create diversity. Depending on the scope, future studies may add or exclude elements, such as considering the necessity of mouse-specific microbionts obtained through the inclusion of feral mice. While the basis for environmental diversity will inevitably vary between geographical sites (Linnenbrink et al., 2013; Kreisinger et al., 2014), so does the microbiota in highly isolated conventional facilities (Rausch et al., 2016). The strength of genetically controlled model animals remains, and studies on the background of mice feralized in this manner can complement studies in conventional SPF and germ-free lab mice, as demonstrated by us in two reports (Lindner et al., 2015; Monin et al., 2020). By ensuring that environmental materials derive from the same sources throughout the experiment, and preferably between experiments, well-controlled and reproducible experiments can be achieved. A "dirty" environment as described here must in most cases be established separate from clean mouse houses, in our hands successfully achieved in an experimental large animal facility, and later built as a separate satellite unit.

\section{CONCLUSION}

In conclusion, we have demonstrated how laboratory mice can be feralized in large pens containing feral cohabitant mice, recapitulating a natural mouse habitat. Feralized mice reproducibly carried an altered fecal microbiota and immunophenotype in systemic immune tissues. This model system represents a refinement opportunity for various purposes, such as assessing the performance of infections, drugs or vaccines on the background of "real-world" adapted animals.

\section{DATA AVAILABILITY STATEMENT}

The original contributions presented in the study are publicly available. This data can be found in NCBI, under accession number PRJNA668303.

\section{ETHICS STATEMENT}

The animal study was reviewed and approved by National Animal Research Authority, Norwegian Food Safety Authority. 


\section{AUTHOR CONTRIBUTIONS}

$\mathrm{PB}$ and AKS designed the research. $\mathrm{BWH}$ and $\mathrm{PB}$ conducted animal Exp. 1. LEK and PB conducted animal Exp. 2 and 3. $\mathrm{BWH}, \mathrm{LEK}, \mathrm{GMJ}, \mathrm{MB}, \mathrm{OP}$, and $\mathrm{PB}$ performed the laboratory procedures. $\mathrm{HA}$ and $\mathrm{PB}$ analyzed the data and wrote the manuscript. All authors contributed to the article and approved the submitted version.

\section{FUNDING}

This research was funded internally at NMBU and the collaborators, microbiota analyses was supported by a grant from The Nansen Fund (Unifor, Norway).

\section{ACKNOWLEDGMENTS}

We are indebted to Jane Hurst (University of Liverpool, United Kingdom) for valuable advice on the design of the mouse pens, the staff at Department of ProdMed at NMBU for assistance with the pen constructions and monitoring of mice (and for keeping the cat out!), the staff at ExBio (NMBU) for housing and tending of control mice, Andrew Janczak (NMBU) for lending of surveillance cameras, Teresa Hagen (NMBU, Parasitology group) for parasitological examinations, Peter O. Hofgaard (University of Oslo, Department of Immunology at Oslo University Hospital), Profs. Jan E. Paulsen and Harald Carlsen (NMBU) for advice on animal dissection and lab methods, Johanna Kabbert, Christina Petrick, Thomas Hitch (RWTH Aachen, Germany), and Anne Mari Herfindal (NMBU) for help and discussions related to the microbiota analyses.

\section{SUPPLEMENTARY MATERIAL}

The Supplementary Material for this article can be found online at: https://www.frontiersin.org/articles/10.3389/fmicb. 2020.615661/full\#supplementary-material

Supplementary Figure 1 | Flow cytometry gating strategies. (A) Single cell, mononuclear cells (MNC) and live cell gates. (B) NK cells defined as NKp46+CD3- cells, further defined as maturational stages S1-S4 based on CD27

\section{REFERENCES}

Abolins, S., King, E. C., Lazarou, L., Weldon, L., Hughes, L., Drescher, P., et al. (2017). The comparative immunology of wild and laboratory mice, Mus musculus domesticus. Nat. Commun. 8:14811. doi: 10.1038/ncomms14811

Abolins, S., Lazarou, L., Weldon, L., Hughes, L., King, E. C., Drescher, P., et al. (2018). The ecology of immune state in a wild mammal, Mus musculus domesticus. PLoS Biol. 16:e2003538. doi: 10.1371/journal.pbio.2003538

Abolins, S. R., Pocock, M. J., Hafalla, J. C., Riley, E. M., and Viney, M. E. (2011). Measures of immune function of wild mice, Mus musculus. Mol. Ecol. 20, 881-892. doi: 10.1111/j.1365-294x.2010.04910.x

Antweiler, R. C. (2015). Evaluation of statistical treatments of left-censored environmental data using coincident uncensored data sets. II. Group and CD11b expression, or gated for the expression of KLRG1. (C) T-cells gated equivalent to above, gated as $\mathrm{CD}^{+}$or $\mathrm{CD}^{+}$and defined as Central Memory $\left(\mathrm{CM}\right.$; CD62L $\left.{ }^{+} \mathrm{CD}_{4}{ }^{+}\right)$or Effector Memory (EM; CD62L-CD44+). (D) Regulatory T-cells, gated on CD4+ T-cells equivalent to above, defined as CD25+Foxp3+, and further gated for the expression of Neuropilin-1 (NRP1). (E) In vitro stimulated T-cells, cultured for $48 \mathrm{~h}$ in the presence of CD3/CD28 activator beads and IL-2, gated on T-cells equivalent to above and gated for the expression of interferon gamma (IFNg).

Supplementary Figure 2 | Photos from the mouse experiments carried out in the farmyard-like pens. (A) Pallet, soil, large animal feces, twigs, straw, feral mice. (B) Feral mouse peeking from water bottle. (C) Nest with B6 $x$ feral mouse crosses. (D) B6 mice checking box (mostly used as toilets; dirt holes were preferred as nests). (E) Feral mouse. (F) Nighttime grazing on sprouts. (G) Offspring playing in box.

Supplementary Figure 3 | Natural killer (NK) cell numbers and phenotypes in spleen, equivalent to Figure 7. Abbreviations and statistics as in Figure 4

Supplementary Figure 4 | Gut microbiota diversity and composition of SPF mice fed different diets. Presented data is from Exp. 3. (A) Multi-dimensional scaling (MDS) plot of microbiota profiles for seed- and chow-fed animals at baseline (t0) and termination ( $\mathrm{t} 1$ ). Similarities between profiles were computed using generalized Unifrac distances. The significance of separation between groups was tested by PERMANOVA. $d$ = dissimilarity scale. (B) Richness (observed OTUs) and Shannon effective diversity index. Box plots show median (line), mean (+), IQR (box) and minimum to maximum (whiskers). Asterisks designate over-time differences determined by Wilcoxon Signed-Rank Sum test. Letters designate differences between groups at each timepoint determined by Kruskal-Wallis and Mann-Whitney $U$ tests. The Benjamini-Hochberg method was used to correct for multiple testing. Different letters designate statistical significance with corrected $p \leq 0.05$. ${ }^{*} p \leq 0.05,{ }^{* *} p \leq 0.01,{ }^{* * *} p \leq 0.001$. (C) Taxonomic binning at the rank of phylum, presented as relative abundance for each individual, with groups and timepoints indicated. (D) Firmicutes/Bacteroidetes ratio presented as in (B). (E) Heatmap of relative abundances of Chow- and Seed-associated OTUs identified by indicator species analysis. Phyla of which the OTUs belong to are designated with colored squares specified in (C). Relative abundances of the OTUs $<0.25 \%$ were set to NA (black). All plots: $n=12$ (chow) or $n=13$ (seed).

Supplementary Figure 5 | Cellular immunological phenotypes of mice in Exp. 3 , corresponding to measurements in main experiments shown in Figures 4-7. Abbreviations and statistics as in Figure 4.

Supplementary Video 1 | Mouse pen overview, wooden pallets, soil heaps with fresh domestic animal manure, straw, spruce twigs. / C57BL/6 mice in farm environment.

Supplementary Video 2 | Release of feral (wild-caught) mouse. / First encounters between C57BL/6 and feral mice.

Supplementary Video 3 | Feral mouse showing agile behavior, use of available space and resources.

Supplementary Video 4 | Feral mice showing curiosity, adaptability to B6 mice and people.

comparisons. Environ. Sci. Technol. 49, 13439-13446. doi: 10.1021/acs.est. $5 \mathrm{~b} 02385$

Balcombe, J. (2010). Laboratory rodent welfare: thinking outside the cage. J. Appl. Anim. Welf. Sci. 13, 77-88. doi: 10.1080/10888700903372168

Beura, L. K., Hamilton, S. E., Bi, K., Schenkel, J. M., Odumade, O. A., Casey, K. A., et al. (2016). Normalizing the environment recapitulates adult human immune traits in laboratory mice. Nature 532, 512-516. doi: 10.1038/nature17655

Bilate, A. M., and Lafaille, J. J. (2012). Induced CD4+Foxp3+ Regulatory T Cells in immune tolerance. Annu. Rev. Immunol. 30, 733-758. doi: 10.1146/annurevimmunol-020711-075043

Boursot, P., Auffray, J. C., Britton-Davidian, J., and Bonhomme, F. (1993). The evolution of house mice. Annu. Rev. Ecol. Syst. 24, 119-152. doi: 10.1146/ annurev.es.24.110193.001003 
Boysen, P., Eide, D. M., and Storset, A. K. (2011). Natural killer cells in freeliving Mus musculus have a primed phenotype. Mol. Ecol. 20, 5103-5110. doi: 10.1111/j.1365-294X.2011.05269.x

Cebra, J. J. (1999). Influences of microbiota on intestinal immune system development. Am. J. Clin. Nutr. 69, 1046S-1051S.

Chai, J. N., Peng, Y., Rengarajan, S., Solomon, B. D., Ai, T. L., Shen, Z., et al. (2017). Helicobacter species are potent drivers of colonic $\mathrm{T}$ cell responses in homeostasis and inflammation. Sci. Immunol. 2:eaal5068. doi: 10.1126/ sciimmunol.aal5068

Chen, J., Bittinger, K., Charlson, E. S., Hoffmann, C., Lewis, J., Wu, G. D., et al. (2012). Associating microbiome composition with environmental covariates using generalized UniFrac distances. Bioinformatics 28, 2106-2113. doi: 10. 1093/bioinformatics/bts342

Chiossone, L., Chaix, J., Fuseri, N., Roth, C., Vivier, E., and Walzer, T. (2009). Maturation of mouse NK cells is a 4-stage developmental program. Blood 113, 5488-5496. doi: 10.1182/blood-2008-10-187179

Chung, H., Pamp, S. J., Hill, J. A., Surana, N. K., Edelman, S. M., Troy, E. B., et al. (2012). Gut immune maturation depends on colonization with a host-specific microbiota. Cell 149, 1578-1593. doi: 10.1016/j.cell.2012.04.037

Daniel, H., Gholami, A. M., Berry, D., Desmarchelier, C., Hahne, H., Loh, G., et al. (2014). High-fat diet alters gut microbiota physiology in mice. ISME J. 8, 295-308. doi: 10.1038/ismej.2013.155

De Cáceres, M., and Legendre, P. (2009). Associations between species and groups of sites: indices and statistical inference. Ecology 90, 3566-3574. doi: 10.1890/ 08-1823.1

Desai, M. S., Seekatz, A. M., Koropatkin, N. M., Kamada, N., Hickey, C. A., Wolter, M., et al. (2016). A dietary fiber-deprived gut microbiota degrades the colonic mucus barrier and enhances pathogen susceptibility. Cell 167, 1339-1353.e21. doi: 10.1016/j.cell.2016.10.043

Devalapalli, A. P., Lesher, A., Shieh, K., Solow, J. S., Everett, M. L., Edala, A. S., et al. (2006). Increased levels of IgE and autoreactive, polyreactive IgG in wild rodents: implications for the hygiene hypothesis. Scand. J. Immunol. 64, 125-136. doi: 10.1111/j.1365-3083.2006.01785.x

Dufrene, M., and Legendre, P. (1997). Species assemblages and Indicator species: the need for a flexible asymmetrical approach. Ecol. Monogr. 67, 345-366. doi: $10.2307 / 2963459$

Edgar, R. C. (2004). MUSCLE: multiple sequence alignment with high accuracy and high throughput. Nucleic Acids Res. 32, 1792-1797. doi: 10.1093/nar/gkh340

Edgar, R. C. (2010). Search and clustering orders of magnitude faster than BLAST. Bioinformatics 26, 2460-2461. doi: 10.1093/bioinformatics/btq461

Edgar, R. C., Haas, B. J., Clemente, J. C., Quince, C., and Knight, R. (2011). UCHIME improves sensitivity and speed of chimera detection. Bioinformatics 27, 2194-2200. doi: 10.1093/bioinformatics/btr381

El Aidy, S., van Baarlen, P., Derrien, M., Lindenbergh-Kortleve, D. J., Hooiveld, G., Levenez, F., et al. (2012). Temporal and spatial interplay of microbiota and intestinal mucosa drive establishment of immune homeostasis in conventionalized mice. Mucosal Immunol. 5, 567-579. doi: 10.1038/mi.2012.32

Flies, A. S., and Wild Comparative Immunology Consortium (2020). Rewilding immunology. Science 369, 37-38. doi: 10.1126/science.abb8664

Franklin, C. L., and Ericsson, A. C. (2017). Microbiota and reproducibility of rodent models. Lab Anim. 46, 114-122. doi: 10.1038/laban.1222

Frossard, C. P., Lazarevic, V., Gaia, N., Leo, S., Doras, C., Habre, W., et al. (2017). The farming environment protects mice from allergen-induced skin contact hypersensitivity. Clin. Exp. Allergy 47, 805-814. doi: 10.1111/cea.12905

Gray, S. J., Jensen, S. P., and Hurst, J. L. (2000). Structural complexity of territories: preference, use of space and defence in commensal house mice, Mus domesticus. Anim. Behav. 60, 765-772. doi: 10.1006/anbe.2000.1527

Honda, K., and Littman, D. R. (2016). The microbiota in adaptive immune homeostasis and disease. Nature 535, 75-84. doi: 10.1038/nature18848

Huggins, M. A., Sjaastad, F. V., Pierson, M., Kucaba, T. A., Swanson, W., Staley, C., et al. (2019). Microbial exposure enhances immunity to pathogens recognized by TLR2 but increases susceptibility to cytokine storm through TLR4 sensitization. Cell Rep. 28, 1729. doi: 10.1016/j.celrep.2019.07.028

Hunter, P. (2020). Public Health struggles to square hygiene with diversity: research on the link between microbiomes and immune function puts the "hygiene hypothesis" to rest. EMBO Rep. 21:e51540. doi: 10.15252/embr. 202051540
Ivanov, I. I., Atarashi, K., Manel, N., Brodie, E. L., Shima, T., Karaoz, U., et al. (2009). Induction of intestinal Th17 cells by segmented filamentous bacteria. Cell 139, 485-498. doi: 10.1016/j.cell.2009.09.033

Jakobsson, H. E., Rodriguez-Pineiro, A. M., Schutte, A., Ermund, A., Boysen, P., Bemark, M., et al. (2015). The composition of the gut microbiota shapes the colon mucus barrier. EMBO Rep. 16, 164-177. doi: 10.15252/embr.201439263

Jensen, S. P., Gray, S. J., and Hurst, J. L. (2003). How does habitat structure affect activity and use of space among house mice? Anim. Behav. 66, 239-250. doi: 10.1006/anbe.2003.2184

Jensen, S. P., Gray, S. J., and Hurst, J. L. (2005). Excluding neighbours from territories: effects of habitat structure and resource distribution. Anim. Behav. 69, 785-795. doi: 10.1016/j.anbehav.2004.07.008

Knutsen, L. E., Dissen, E., Saether, P. C., Bjornsen, E. G., Pialek, J., Storset, A. K., et al. (2019). Evidence of functional Cd94 polymorphism in a free-living house mouse population. Immunogenetics 71, 321-333. doi: 10.1007/s00251018-01100- $\mathrm{x}$

Kreisinger, J., Cizkova, D., Vohanka, J., and Pialek, J. (2014). Gastrointestinal microbiota of wild and inbred individuals of two house mouse subspecies assessed using high-throughput parallel pyrosequencing. Mol. Ecol. 23, 50485060. doi: 10.1111/mec.12909

Kriegel, M. A., Sefik, E., Hill, J. A., Wu, H. J., Benoist, C., and Mathis, D. (2011). Naturally transmitted segmented filamentous bacteria segregate with diabetes protection in nonobese diabetic mice. Proc. Natl. Acad. Sci. U.S.A. 108, 11548-11553. doi: 10.1073/pnas.1108924108

Lagkouvardos, I., Fischer, S., Kumar, N., and Clavel, T. (2017). Rhea: a transparent and modular $\mathrm{R}$ pipeline for microbial profiling based on 16S rRNA gene amplicons. PeerJ 5:e2836. doi: 10.7717/peerj.2836

Lagkouvardos, I., Joseph, D., Kapfhammer, M., Giritli, S., Horn, M., Haller, D., et al. (2016). IMNGS: a comprehensive open resource of processed 16S rRNA microbial profiles for ecology and diversity studies. Sci. Rep. 6:33721. doi: 10. 1038/srep33721

Las Heras, V., Clooney, A. G., Ryan, F. J., Cabrera-Rubio, R., Casey, P. G., Hueston, C. M., et al. (2019). Short-term consumption of a high-fat diet increases host susceptibility to Listeria monocytogenes infection. Microbiome 7:7. doi: 10.1186/ s40168-019-0621-x

Leung, J. M., Budischak, S. A., The, H. C., Hansen, C., Bowcutt, R., Neill, R., et al. (2018). Rapid environmental effects on gut nematode susceptibility in rewilded mice. PLoS Biol. 16:e2004108. doi: 10.1371/journal.pbio.2004108

Liddicoat, C., Sydnor, H., Cando-Dumancela, C., Dresken, R., Liu, J., Gellie, N. J. C., et al. (2020). Naturally-diverse airborne environmental microbial exposures modulate the gut microbiome and may provide anxiolytic benefits in mice. Sci. Total Environ. 701:134684. doi: 10.1016/j.scitotenv.2019. 134684

Lin, J. D., Devlin, J. C., Yeung, F., McCauley, C., Leung, J. M., Chen, Y. H., et al. (2020). Rewilding Nod2 and Atg16l1 mutant mice uncovers genetic and environmental contributions to microbial responses and immune cell composition. Cell Host Microbe 27, 830-840.e4. doi: 10.1016/j.chom.2020. 03.001

Lindner, C., Thomsen, I., Wahl, B., Ugur, M., Sethi, M. K., Friedrichsen, M., et al. (2015). Diversification of memory B cells drives the continuous adaptation of secretory antibodies to gut microbiota. Nat. Immunol. 16, 880-888. doi: 10.1038/ni.3213

Linnenbrink, M., Wang, J., Hardouin, E. A., Kunzel, S., Metzler, D., and Baines, J. F. (2013). The role of biogeography in shaping diversity of the intestinal microbiota in house mice. Mol. Ecol. 22, 1904-1916. doi: 10.1111/mec.12206

Monin, L., Ushakov, D. S., Arnesen, H., Bah, N., Jandke, A., Munoz-Ruiz, M., et al. (2020). gammadelta $\mathrm{T}$ cells compose a developmentally regulated intrauterine population and protect against vaginal candidiasis. Mucosal Immunol. 13, 969-981. doi: 10.1038/s41385-020-0305-7

Muraille, E., and Goriely, S. (2017). The nonspecific face of adaptive immunity. Curr. Opin. Immunol. 48, 38-43. doi: 10.1016/j.coi.2017.08.002

Nabekura, T., and Lanier, L. L. (2016). Tracking the fate of antigen-specific versus cytokine-activated natural killer cells after cytomegalovirus infection. J. Exp. Med. 213, 2745-2758. doi: 10.1084/jem.20160726

Netea, M. G., Dominguez-Andres, J., Barreiro, L. B., Chavakis, T., Divangahi, M., Fuchs, E., et al. (2020). Defining trained immunity and its role in health and disease. Nat. Rev. Immunol. 20, 375-388. doi: 10.1038/s41577-020-0285-6 
Oh, J. Z., Ravindran, R., Chassaing, B., Carvalho, F. A., Maddur, M. S., Bower, M., et al. (2014). TLR5-mediated sensing of gut microbiota is necessary for antibody responses to seasonal influenza vaccination. Immunity 41, 478-492. doi: 10.1016/j.immuni.2014.08.009

Ottman, N., Ruokolainen, L., Suomalainen, A., Sinkko, H., Karisola, P., Lehtimaki, J., et al. (2019). Soil exposure modifies the gut microbiota and supports immune tolerance in a mouse model. J. Allergy Clin. Immunol. 143, 1198. doi: 10.1016/j. jaci.2018.06.024

Pocock, M. J., Hauffe, H., and Searle, J. B. (2005). Dispersal in house mice. Biol. J. Linn. Soc. 84, 565-583. doi: 10.1111/j.1095-8312.2005.00455.x

Price, M. N., Dehal, P. S., and Arkin, A. P. (2010). FastTree 2-approximately maximum-likelihood trees for large alignments. PLoS One 5:e9490. doi: 10. 1371/journal.pone.0009490

Quinn, S. M., Cunningham, K., Raverdeau, M., Walsh, R. J., Curham, L., Malara, A., et al. (2019). Anti-inflammatory trained immunity mediated by helminth products attenuates the induction of $\mathrm{T}$ cell-mediated autoimmune disease. Front. Immunol. 10:1109. doi: 10.3389/fimmu.2019.01109

Rausch, P., Basic, M., Batra, A., Bischoff, S. C., Blaut, M., Clavel, T., et al. (2016). Analysis of factors contributing to variation in the C57BL/6J fecal microbiota across German animal facilities. Int. J. Med. Microbiol. 306, 343-355. doi: 10. 1016/j.ijmm.2016.03.004

Reese, T. A., Bi, K., Kambal, A., Filali-Mouhim, A., Beura, L. K., Burger, M. C., et al. (2016). Sequential infection with common pathogens promotes humanlike immune gene expression and altered vaccine response. Cell Host Microbe 19, 713-719. doi: 10.1016/j.chom.2016.04.003

Rosshart, S. P., Herz, J., Vassallo, B. G., Hunter, A., Wall, M. K., Badger, J. H., et al. (2019). Laboratory mice born to wild mice have natural microbiota and model human immune responses. Science 365:eaaw4361. doi: 10.1126/science. aaw4361

Rosshart, S. P., Vassallo, B. G., Angeletti, D., Hutchinson, D. S., Morgan, A. P., Takeda, K., et al. (2017). Wild mouse gut microbiota promotes host fitness and improves disease resistance. Cell 171, 1015-1028.e13. doi: 10.1016/j.cell.2017. 09.016

R_Core_Team (2020). R: A Language and Environment for Statistical Computing. Vienna: R Foundation for Statistical Computing.

Seedorf, H., Griffin, N. W., Ridaura, V. K., Reyes, A., Cheng, J., Rey, F. E., et al. (2014). Bacteria from diverse habitats colonize and compete in the mouse gut. Cell 159, 253-266. doi: 10.1016/j.cell.2014.09.008

Selander, R. K. (1970). Behavior and genetic variation in natural populations. Am. Zool. 10, 53-66. doi: 10.1093/icb/10.1.53

Stockinger, B., Bourgeois, C., and Kassiotis, G. (2006). CD4+ memory T cells: functional differentiation and homeostasis. Immunol. Rev. 211, 39-48. doi: 10.1111/j.0105-2896.2006.00381.x

Tao, L., and Reese, T. A. (2017). Making mouse models that reflect human immune responses. Trends Immunol. 38, 181-193. doi: 10.1016/j.it.2016.12.007

Trompette, A., Gollwitzer, E. S., Yadava, K., Sichelstiel, A. K., Sprenger, N., NgomBru, C., et al. (2014). Gut microbiota metabolism of dietary fiber influences allergic airway disease and hematopoiesis. Nat. Med. 20, 159-166. doi: 10.1038/ nm.3444

Vezys, V., Yates, A., Casey, K. A., Lanier, G., Ahmed, R., Antia, R., et al. (2009). Memory CD8 T-cell compartment grows in size with immunological experience. Nature 457, 196-199. doi: 10.1038/nature07486

Wang, Q., Garrity, G. M., Tiedje, J. M., and Cole, J. R. (2007). Naive Bayesian classifier for rapid assignment of rRNA sequences into the new bacterial taxonomy. Appl. Environ. Microbiol. 73, 5261-5267. doi: 10.1128/aem. 00062-07

Warnes, G. R., Bolker, B., Bonebakker, L., Gentleman, R., Huber, W., Liaw, A., et al. (2020). Available online at: https://CRAN.R-project.org/package=gplots (accessed December 01, 2020).

Weissbrod, A., Shapiro, A., Vasserman, G., Edry, L., Dayan, M., Yitzhaky, A., et al. (2013). Automated long-term tracking and social behavioural phenotyping of animal colonies within a semi-natural environment. Nat. Commun. 4:2018. doi: $10.1038 /$ ncomms3018

Wherry, E. J., Teichgräber, V., Becker, T. C., Masopust, D., Kaech, S. M., Antia, R., et al. (2003). Lineage relationship and protective immunity of memory CD8 $\mathrm{T}$ cell subsets. Nat. Immunol. 4, 225-234. doi: 10.1038/ ni889

Xiao, L., Sonne, S. B., Feng, Q., Chen, N., Xia, Z., Li, X., et al. (2017). High-fat feeding rather than obesity drives taxonomical and functional changes in the gut microbiota in mice. Microbiome 5:43.

Yang, H., Wang, J. R., Didion, J. P., Buus, R. J., Bell, T. A., Welsh, C. E., et al. (2011). Subspecific origin and haplotype diversity in the laboratory mouse. Nat. Genet. 43, 648-655. doi: 10.1038/ng.847

Yeung, F., Chen, Y. H., Lin, J. D., Leung, J. M., McCauley, C., Devlin, J. C., et al. (2020). Altered immunity of laboratory mice in the natural environment is associated with fungal colonization. Cell Host Microbe 27, 809-822.e6. doi: 10.1016/j.chom.2020.02.015

Yoon, S. H., Ha, S. M., Kwon, S., Lim, J., Kim, Y., Seo, H., et al. (2017). Introducing EzBioCloud: a taxonomically united database of 16S rRNA gene sequences and whole-genome assemblies. Int. J. Syst. Evol. Microbiol. 67, 1613-1617. doi: 10.1099/ijsem.0.001755

Conflict of Interest: The authors declare that the research was conducted in the absence of any commercial or financial relationships that could be construed as a potential conflict of interest.

Copyright (C) 2021 Arnesen, Knutsen, Hognestad, Johansen, Bemark, Pabst, Storset and Boysen. This is an open-access article distributed under the terms of the Creative Commons Attribution License (CC BY). The use, distribution or reproduction in other forums is permitted, provided the original author(s) and the copyright owner(s) are credited and that the original publication in this journal is cited, in accordance with accepted academic practice. No use, distribution or reproduction is permitted which does not comply with these terms. 